\title{
PROPOSICIONES RESPECTO DE LAS CUESTIONES NO RESUELTAS POR LA LEY N²0.084 EN MATERIA DE ACUMULACIÓN Y ORDEN DE CUMPLIMIENTO DE LAS PENAS*
}

\author{
Jean Pierre Matus Acuña**
}

\section{Introducción}

En el relación a varias situaciones producidas ante Tribunales de Garantía y de Juicio Oral, con motivo de la aplicación de la Ley N $\mathrm{N}^{\mathrm{0}} 20.084$, sobre Responsabilidad Penal de los Adolescentes, la Defensoría Penal Pública me ha formulado las siguientes cuestiones relativas a la acumulación y orden de cumplimiento de las penas, medidas y sanciones que en ella y en el Código Penal se establecen:

a) ¿Cuál es el orden de cumplimiento de cumplimiento de diversas penas que se imponen?

b) “Qué criterios debemos considerar para resolver este problema?

c) ¿Tienen relevancia los fines de la pena, especialmente lo dispuesto en el Art.20 de la Ley $\mathrm{N}^{\mathrm{o}} 20.084$ ?

d) “Puede considerarse la opinión del condenado?

e) ¿Cuál es el lugar de cumplimiento?

f) “Cómo se interpreta o aplica el Artículo 164 del Código Orgánico de Tribunales?

g) ¿Cómo se interpretan o aplican los Artículos 74 del Código Penal y 351 del Código Procesal Penal?

h) “Cómo entender el concepto de pena más grave del Art.74 o pena menor del Art.351 del Código Procesal Penal, especialmente cuando se comparan una pena privativa de libertad con otra no privativa de libertad y la extensión de esta última es mayor?"

* El presente informe fue elaborado a solicitud de la Defensoría Penal Pública, por Resolución Exenta 2458 de 10.10 .2008 .

* Director del Centro de Estudios de Derecho Penal de la Universidad de Talca. Correo electrónico: jpmatusa@utalca.cl 
Las situaciones en que estas preguntas serían aplicables, se resumirían en los siguientes supuestos, planteados por los requirentes del Informe:

a) "Situación del condenado menor de edad a dos o más penas de la Ley 20.084 de distinta naturaleza.

b) "Situación del imputado condenado a 2 o más penas de sistema adolescente y de adulto, de igual naturalezas entre sí.

c) "Situación del imputado condenado a 2 o más penas de sistema adolescente y de adulto."

Para una adecuada respuesta a estas cuestiones, parece necesario clarificar, en primer término, el régimen general de acumulación material, reiteración de delitos y unificación de penas en el Código Penal y en la Ley $\mathrm{N}^{\mathrm{0}} 20.084$, para, a continuación, proceder a analizar las cuestiones que surgen de la potencial combinación de ambos sistemas.

Por lo tanto, las cuestiones planteadas no serán resueltas sucesivamente, sino en el orden que impone la sistematización de los problemas que se ha propuesto. ${ }^{1}$

\section{El régimen concursal general en el Código Penal}

\subsection{Regla general del régimen concursal chileno: presupuestos de aplicación del art. $74 \mathrm{CP}$ y su relación con el artículo 451 CPP}

Como lo he expuesto en obras anteriores, ${ }^{2}$ el problema del concurso o pluralidad de delitos se presenta cuando, en un mismo proceso, se puede imputar a una persona la realización

1 Para evitar confusiones, no se hará en este informe sino marginalmente referencia a los problemas de aplicación temporal de la ley penal, asumiendo que ellos están resueltos antes de hacerse las preguntas correspondientes a los concursales, que suponen la fijación previa de la ley aplicable y cuya aplicación genera el fenómeno concursal. Tampoco se abordarán los problemas relativos a la ejecución de las sanciones establecidas en la Ley $\mathrm{N}^{\circ} 20.084$ y sus variantes prácticas, pro exceder del tema concursal, que debe, a este respecto, fijarse previamente.

2 MATUS, Jean Pierre, "Comentario a los artículos 74 a 78”, en: POLITOFF, Sergio; ORTIZ, Luis; MATUS, Jean Pierre, Texto y Comentario del Código Penal Chileno, t. I, Santiago: Ed. Jurídica de Chile, 2002, pp. 383-407. También en POLITOFF, Sergio; MATUS, Jean Pierre; RAMÍREZ, Ma Cecilia, Lecciones de Derecho Penal Chileno, Parte General, $2^{a}$ ed., Santiago: Ed. Jurídica de Chile, 2004, pp. 445-467. Al respecto, cabe señalar que aquí se hace no sólo una aproximación más detallada al tema que en estas obras generales, sino también una sutil pero importante diferenciación -que no se encuentra en los textos citados-, entre reglas concursales especiales y otras propiamente excepcionales, considerando entre las primeras a aquellas que permiten eventualmente el tratamiento de sus supuestos de hecho conforme a la regla general del art. $74 \mathrm{CP}$ (arts. $75 \mathrm{CP}$ y $351 \mathrm{CPP}$, así como los casos de concurso aparente de leyes); y entre las segundas, a las que no lo permiten (ver nota al pie $\mathrm{n}^{\mathrm{o}} 8$ ). 
Proposiciones respecto de las cuestiones no resueltas por la Ley $\mathrm{N}^{\mathrm{o}} 20.084$

en materia de acumulación y orden de cumplimiento de las penas

del supuesto de hecho de varios tipos penales o varias veces el de uno mismo ${ }^{3}$, cuya regla general de tratamiento penológico es la de la acumulación material de penas que se encuentra en el inc. $1^{\circ}$ del art. 74: «al culpable de dos o más delitos se le impondrán todas las penas correspondientes a las diversas infracciones».

Los presupuestos esenciales para la aplicación de esta regla penológica son dos: a) que se trate de un mismo imputado; y b) que se le condene por dos o más delitos en un mismo proceso o en varios procesos separados, siempre que entre el momento de la realización de un delito y del otro no haya existido una condena. ${ }^{4}$

El tratamiento penal en estos casos es la aplicación de la aparentemente sencilla regla penológica de la acumulación material de penas: se debe determinar en concreto la pena correspondiente a cada delito por separado, esto es, tomando en cuenta "todas las circunstancias" del caso; y luego, acumularlas para su aplicación. Las complicaciones que provoca este concurso de penas sobreviniente las estudiaremos en el apartado siguiente. Por de pronto, sólo diremos que la racionalidad de este sistema se aprecia con claridad a la luz del principio de igualdad ante la ley, si se compara esta situación con la del condenado por un delito cometido con posterioridad a una condena anterior: en ambos casos se servirían todas las penas impuestas, con la única diferencia que en el último de los supuestos, sería posible apreciar la agravante de reincidencia. ${ }^{5}$

Sin embargo, a partir de esta sencilla regla general encontramos una serie de casos especiales, donde se tiende a morigerar los aparentemente rigurosos efectos de la regla general

3 Por eso tiene razón JESCHECK, H.-H., "Die Konkurrenz", en ZStW 67 (1955), 529, cuando afirma que si no tuviésemos un sistema penal en el que prima el principio de legalidad, el problema concursal no existiría, ya que la norma penal aplicable siempre sería una sola (la infracción al derecho). Sin embargo, al contrario de lo que se pensaba en buena parte del siglo pasado, nada hay de ontológico o impuesto por el propio sistema en la distinción entre las diferentes clases de concursos delictivos. Se trata en general, y como lo demuestran las múltiples y variadas formas de tratamiento del concurso de delitos en la legislación comparada y en la nuestra, de decisiones de política criminal, acordes con el mayor o menor sentimiento de humanidad y racionalidad de cada legislación y comunidad en particular: así, por ejemplo, mientras en España la ley obliga, en definitiva, a elegir el régimen concursal más favorable al acusado, en Chile, aun sin expresa regulación legal, nuestra jurisprudencia tiende sistemáticamente a elegir entre una y otra forma de concurso, aquella que sea más favorable al reo.

$4 \quad$ El requisito adicional que suele agregar nuestra doctrina, esto es, de que se trate de un supuesto de "pluralidad de hechos" (ETCHEBERRY, Alfredo, Derecho Penal, Parte General, t. II, $3{ }^{a}$ ed., Santiago: Ed. Jurídica de Chile, 1998, p. 115), no es exigido por el texto de la ley y, aunque este requisito se desprende de una interpretación sistemática con relación al art. $75 \mathrm{CP}$ (casos de concurso ideal), el carácter general y subsidiario que tiene el art. 74 -como se explicará enseguida- no permite extender a éste, a contrario sensu, los requisitos de aplicación de una regla excepcional ("unidad de hecho" del art. $75)$, pues de otro modo se imposibilitaría la aplicación subsidiaria del mencionado art. 74 a los casos en que resulte más favorable para el condenado que la regla excepcional del art. 75.

5 FUENZALIDA, Alejandro, Concordancias y Comentarios al Código Penal Chileno, t. I, Lima: 1883, p. 320 . 
Jean Pierre Matus Acuña

del art. $74 \mathrm{CP}$ y que, por lo mismo, son de gran importancia en la vida práctica del derecho, como las reglas legales del art. 75 del Código Penal, que establecen los llamados concursos ideal y medial, ${ }^{6}$ y las doctrinales del concurso aparente de leyes..$^{7-8}$

Es entre este grupo de casos especiales donde se encuentra la regla del artículo 351 del Código Procesal Penal que, reformando levemente lo dispuesto en el art. 409 del Código de Procedimiento Penal de 1906, ha establecido un tratamiento penológico diferenciado (exasperación de la pena más grave en vez de acumulación de todas las concurrentes) ${ }^{9}$ para

6 Como bien destaca CURY, Enrique, Derecho Penal, Parte General, $7^{a}$ ed. ampliada, Santiago: Ed. Universidad Católica de Chile, 2005, pp. 662, el concurso medial sería, en realidad, un supuesto especial de concurso real con el mismo régimen penológico (absorción) que el concurso ideal. Sin embargo, desde nuestra perspectiva, cabe señalar que consideramos también al concurso ideal como un supuesto especial de concurso real, y no como un caso conceptualmente diferenciado o antagónico, según lo aprecia la doctrina chilena mayoritaria. Por otra parte, cabe destacar que según nuestra doctrina más autorizada «los ejemplos de auténtico concurso ideal que pueden proponerse son escasos y muchos de ellos de índole más bien académica» (NOVOA, Eduardo, Curso de Derecho Penal, t. II, Santiago, Ed. Jurídica de Chile: 1960 (reimp. 2005), 262), pues «el cada vez más fino análisis de los tipos penales y sus relaciones entre sí ha ido reduciendo la importancia práctica del concurso ideal» (ETCHEBERRY, Derecho Penal, II, cit. en nota $\mathrm{n}^{\mathrm{o}} 4$, p. 122). A ello debe sumarse que la distinción entre concurso ideal heterogéneo y homogéneo, ha conducido a que en este último caso, donde el tipo penal infringido sería el mismo (p. ej., dar muerte a varias personas con un solo artefacto explosivo), a pesar de existir una única acción o hecho, se tienda a considerar impropia la rebaja penológica, optándose derechamente por la regla general del art. 74 (GARRIDO MONTT, Mario, Derecho Penal, Parte General, t. II, Santiago: Ed. Jurídica de Chile, 1997, p. 338).

7 Al respecto, véase mi reciente MATUS, Jean Pierre, El Concurso Aparente de Leyes, Ed. Jurídicas Santiago: 2008, $430 \mathrm{pp}$.

8 En cambio, parecen auténticas excepciones a estos regímenes concursales serían los casos en que, a pesar de existir realización de varios supuestos típicos o de un mismo tipo varias veces, la ley impone considerarlos un único delito (la llamada unidad jurídica de acción), o establece una solución concursal especifica para un delito o grupo de delitos determinados (art. 141 in fine $\mathrm{CP}, 150 \mathrm{~A} \mathrm{CP}$ ), sin que sea posible volver a la regla general del art. 74. Idéntica parece ser la situación en el caso de la llamada reiteración de hurtos, del art. $451 \mathrm{CP}$. sobre todo por la posibilidad expresa que otorga la ley de sumar las cuantías de los hurtos-falta para construir un simple delito, lo cual evidentemente excluye la imposición de penas de hurto-falta simultáneas y, muchas veces, más beneficiosas para el condenado, al menos en teoría (Cfr. POLITOFF, Sergio; MATUS, Jean Pierre; RAMÍREZ, Ma Cecilia, Lecciones de Derecho Penal Chileno, Parte Especial, $2^{a}$ ed., Santiago: Ed. Jurídica de Chile, 2005, p. 382.).

9 La denominación exasperación para esta forma de tratamiento penal, que sólo "conceptualmente" puede considerarse menos rigorosa que la simple acumulación material, pues en la práctica no necesariamente es así, como veremos enseguida, se encontraba también en la doctrina española, cuando se refería a un similar tratamiento penal de la regla del delito continuado del antiguo art. 69 bis CP 1944 (CUERDA RIEZU, Antonio, Concurso de delitos y determinación de la pena, Madrid: Tecnos, 1992, p. 97), hoy recogido en el art. 74 CP 1995, cuya regulación es similar a la anterior (véase MIR PUIG, Santiago, Derecho Penal, Parte General, $8^{a}$ ed., Montevideo: BdF, 2004, pp. 636-639). Con todo, la aparente divergencia de conceptos ("delito continuado" vs. "reiteración"), el tratamiento penal de los casos comprendidos, que en la versión del art. 69 bis CP 1944 suponía distinguir entre infracciones que podían apreciarse como una sola (delitos contra la propiedad, por ejemplo) y aquéllas en que sólo cabía empezar la agravación desde "la más grave", parece indicar que dicha distinción no es tan categórica, y, sobre todo, que en Chile existe una solución legal para estos casos (los arts. 49 CPP 1906, hoy 351 CPP 2000, y 451 CP) como entre nosotros sostuviese NOVOA, Curso, $t$. II, cit. en nota n ${ }^{\circ}$, pp. 241-244. 
Proposiciones respecto de las cuestiones no resueltas por la Ley $\mathrm{N}^{\mathrm{o}} 20.084$

en materia de acumulación y orden de cumplimiento de las penas

un grupo de casos específico de castigo al culpable de dos o más delitos: el de la reiteración de delitos.

No obstante, como el propio texto del art. 351 CPP señala, el carácter especial de su regulación se encuentra limitado por la posibilidad de que el resultado de su aplicación al caso concreto resulte más gravoso para el condenado que la simple aplicación de la regla general de acumulación material del art. $74 \mathrm{CP} .{ }^{10}$ La cuestión acerca de cuándo una pena determinada conforme al art. $351 \mathrm{CPP}$ pueda considerarse más gravosa que la simple acumulación material ordenada por el art. $74 \mathrm{CP}$, será abordada en los apartados siguientes.

Por el momento, concluiremos diciendo que es posible afirmar que en la aplicación práctica de la regla del art. $351 \mathrm{CPP}$ (como así también sucede respecto de la del art. $75 \mathrm{CP}$ ), lo que predomina son consideraciones de carácter puramente contingente y humanitario, "ya que su finalidad es imponer sanciones menos rigurosas al delincuente, y no más graves; de modo que si su aplicación no logra tal propósito, debe estarse al sistema general de acumulación material del art. 74", ${ }^{11}$ con lo cual éste se transforma, de paso, también en la regla subsidiaria de nuestro sistema concursal. ${ }^{12}$

\subsection{Tratamiento penal de la regla concursal general y subsidiaria del art. 74: la acumulación material y el problema del orden de ejecución de "todas las condenas impuestas"}

Como ya señalamos, la regla penológica del art. 74, que opera como regla general y subsidiaria de nuestro sistema concursal, establece el sistema de acumulación material de penas,

10 Esta suerte de preferencia por la regla más favorable en orden a la duración de la pena también ha sido recogida por nuestra jurisprudencia para los casos del llamado concurso ideal y medial (Cfr. ETCHEBERRY, Afredo, El Derecho Penal en la Jurisprudencia, t. IV, $2^{a}$ ed., Santiago: Ed. Jurídica de Chile, 1987, pp. 204s.).

11 GARRIDO MONTT, Derecho Penal, II, cit. en nota al pie nº 6, p. 347.

12 La misma función cumple la regla de la acumulación material en el derecho español, lo que, según CUERDA, Concurso, cit, nota $n^{\circ}$ 9, pp. 49-53, habría producido cierta desprolijidad en la Jurisprudencia, la cual critica por considerar que siempre el concurso ideal o medial (y el delito continuado), debieran tener una pena menor que el concurso real. Los argumentos del autor no son en absoluto convincentes, pues se basan únicamente en la afirmación de esta supuesta menor gravedad de esta clase de concursos, lo cual es un asunto contingente (p. ej., el Anteproyecto de Código Penal Chileno de 2005, establece un único sistema concursal de acumulación jurídica para las penas privativas y restrictivas de libertad, similar al del actual art. $351 \mathrm{CPP}$, manteniendo la acumulación material como regla general para todas las otras penas y, además, como subsidiaria, en caso de ser más favorable al condenado: MATUS, Jean Pierre; HERNÁNDEZ, Héctor, "Materiales de Discusión presentados a la Comisión Foro Penal, Parte General", Política Criminal, no 1 (2006), D2, p. 1-223, pp. 194-196, en http://www.politicacriminal.cl/ n_01/pdf_01/d_2.pdf) y, llevado a la práctica, originaría considerar siempre "menos grave" la elección de medios estragosos (un hecho) para matar a varios (o a miles, como en el dramático caso del atentado contra las Torres Gemelas), que el simple suceso de matar a dos personas con las manos (véase nota al pie $\mathrm{n}^{\mathrm{o}} 6$, in fine). 
de manera que al condenado habrían de imponérsele "todas las penas correspondientes a las diversas infracciones" juzgadas en el mismo proceso. Como ya advertimos, esto es lo mismo que sucedería si esas diversas infracciones fuesen juzgadas "por separado" y es lo que, de hecho, sucede en los casos de reincidencia.

El problema que suscita esta regla en apariencia sencilla es el del concurso de penas que de ella se deriva: ¿cómo ejecutar todas las penas concurrentes?

El inc. $2^{\circ}$ del art. 74 ofrece la regla general al respecto, ordenando el cumplimiento "simultáneo" de todas las penas impuestas, si ello es posible y no hace "ilusoria alguna de las penas"; o su cumplimiento "en orden sucesivo, principiando por las más graves", si tales condiciones no se cumplen.

Sin embargo, respecto de las penas contempladas en el Código Penal y en la legislación penal especial ordinaria, la regla general ("simultaneidad") tiene un limitado alcance, pues "las únicas penas que pueden cumplirse simultáneamente con otras”, esto es, juntas entre sí y junto a una privativa o restrictiva de libertad, "son las de las inhabilidades, suspensiones, caución y pérdida de los instrumentos y efectos del delito"13 o, en términos más abstractos, "las penas privativas de derechos y las pecuniarias". ${ }^{14}$

En cambio, tratándose de penas privativas y restrictivas de libertad, ellas no pueden cumplirse simultáneamente sin "hacer ilusoria alguna de las penas", frase que no contemplaba

Según DEL RÍO, Raimundo, Derecho Penal, t. II, Santiago: Ed. Nascimento, 1935, p. 359.

LABATUT, Gustavo, Derecho Penal, t. I, $9^{a}$ ed., actualizada por ZENTENO, Julio, Santiago: Ed. Jurídica de Chile, 1995, p. 176. 
Proposiciones respecto de las cuestiones no resueltas por la Ley $\mathrm{N}^{\mathrm{o}} 20.084$

en materia de acumulación y orden de cumplimiento de las penas

el modelo español ${ }^{15}$ y que, en virtud de su inexpresividad legal en dicho cuerpo normativo, había llevado a PACHECO a especular acerca de la posibilidad de su cumplimiento simultáneo, ${ }^{16}$ y por lo tanto, su aplicación ha de hacerse de manera "sucesiva, principiando por las más graves."

Sin embargo, tales especulaciones no tienen cabida en nuestro texto punitivo, no sólo por el agregado en el fraseo del art. $74 \mathrm{CP}$, sino también porque, si ello no fuese suficiente, en la parte final de su inc. $2^{\circ}$, se nos explica detalladamente el orden de imposición sucesiva de las penas privativas y restrictivas de libertad: ha de empezarse por las "más altas" comprendidas en comprendidas en las escalas respectivas, salvo que deban cumplirse sucesivamente penas privativas y restrictivas de libertad, pues en este caso, "las de confinamiento, extrañamiento, relegación y destierro" "se ejecutarán después de haber cumplido cualquiera otra pena de las comprendidas en la escala gradual número 1", esto es, a pesar de encontrarse en un lugar "más alto" en la escala respectiva; excepción que, en sus términos, parece sólo seguir la lógica de no "hacer ilusoria alguna pena", pues se entiende que ella "tiene por objeto evitar que el reo eluda el cumplimiento de las penas privativas de libertad". ${ }^{17}$

15 La frase en cuestión se agregó en el proceso de "revisación" del Código, al aprobar la Comisión Redactora, "sin alteración", algunos de "los artículos cuya redacción se le encomendó" a Manuel Rengifo, como parte de la regulación de todo el sistema de aplicación de penas (Sesión 136, de 13 de mayo de 1873, en: Actas de las Sesiones de la Comisión Redactora del Código Penal Chileno, Santiago: Imprenta de la República, 1873, pp. 241 y 248. En esta acta no se transcribe el artículo del "proyecto" aprobado, pero aparece transcrito en su redacción actual en el Proyecto de Código Penal Chileno, Santiago: Imprenta de la República, 1873, p. 35, aprobado por Comisión Redactora en sesión de 22 de octubre de 1873). La disposición que originalmente había "discutido i aprobado" por "unanimidad" la Comisión Redactora (Sesión 19, de 20 de julio de 1870, Actas , pp. 35 y 40), correspondía al texto art. 76 del modelo español, con una indicación respecto de la referencia a la escala gradual a que se hacía referencia, era la siguiente: "Art. Al culpable de dos o mas delitos o faltas, se le impondrán todas las penas correspondientes a las diversas infracciones.

"El sentenciado las cumplirá simultáneamente, siendo posible; cuando no lo fuere, las sufrirá en órden sucesivo principiando por las mas graves o sean las mas altas en la escala jeneral, escepto las de estrañamiento, confinamiento i destierro, las cuales se ejecutarán despues de haber cumplido cualquiera otra pena de las comprendidas en la escala gradual núm. 1 del art."

Entre ambas sesiones, el tenor de este artículo sólo se discutió a propósito de una indicación del Señor Reyes, quien propuso, durante la discusión de las penas aplicables al homicidio calificado, morigerar los efectos de esta disposición, introduciendo un sistema de absorción en que la pena fuese "el mayor término posible" de "imponer dentro del grado que la lei determina", con el argumento de que con el sistema "de las penas que pueden acumularse por la reiteración de los delitos", "podría llegarse al absurdo de condenar al mismo reo a cuarenta, cincuenta o mas años, lo que equivaldría a un presido perpétuo sin el nombre", idea que contó con el apoyo del Sr. Ibáñez, pero que fue, sin embargo, rechazada por la mayoría de los Comisionados (Sesión 79, de 3 de mayo de 1872, Actas, p. 153).

16 PACHECO, Joaquín Francisco, El Código Penal Concordado y Comentado, $3^{a}$ ed. (1867), con un "Estudio Preliminar y anotaciones de Abel Téllez Aguilera", Madrid: Edisofer, reimp. 2000, p. 410.

17 LABATUT, Derecho Penal, cit. nota $\mathrm{n}^{\circ} 15$, p. 177. 
2.2.1. El problema de determinar cuándo "se hace ilusoria" la ejecución de alguna pena, para los efectos del art. 74 inc. $2^{\circ} \mathrm{CP}$, en casos de penas no contempladas en las escalas graduales del art. 59 .

Como acabamos de señalar, es posible considerar, a nivel abstracto, que la imposición de simultánea de cualquier pena de naturaleza pecuniaria, privativa o restrictiva de derechos no "hace ilusorio" el cumplimiento de otra y que, por lo tanto, a su respecto no cabe hacer especulaciones en orden a su duración temporal o a la intensidad de la privación patrimonial o de derechos para determinar si es o no más grave que otra privativa o restrictiva de libertad.

Por lo tanto, en los casos de penas como la privación de la patria potestad (370 bis), la clausura de establecimientos (art. 368 bis), o la suspensión o inhabilidad perpetua para conducir vehículos a tracción mecánica o animal de la licencia de conducir (art. 492), nada impide su simultánea aplicación con las penas privativas o restrictivas de libertad que se impongan.

Luego, sólo cabría plantear la situación de que existiese la posibilidad, en el régimen penal aplicable a los adultos, de imponer conjuntamente penas privativas o restrictivas de libertad, no comprendidas en las escalas graduales correspondientes. Este es el caso de la pena accesoria de sujeción a la vigilancia de la autoridad, la cual, sin embargo, por expresa disposición del art. $45 \mathrm{CP}$, sigue la misma regla de la parte final del inc. $2^{\circ}$ del art. 74 : se impone al condenado para "después de haber cumplido su condena", atendida su propia naturaleza. Luego, la racionalidad de esta disposición parece suficiente para extenderla a otras eventuales situaciones no reguladas: aunque, en principio, una pena privativa de libertad muy breve puede parecer "menos grave" que una restrictiva de larga duración (y así se refleja por su ubicación en las respectivas escalas graduales), la posibilidad de que durante la ejecución de una pena restrictiva de libertad su incumplimiento haga "ilusoria" la ejecución de la pena privativa de libertad, parece hacer preferible su ejecución en orden inverso, con independencia del tiempo de su duración.

De lo anterior se desprende, además, que las especulaciones acerca de la comparación de la gravedad de las penas, propias de la teoría de la aplicación retroactiva de la ley penal, ${ }^{18}$ no parecen tener en este lugar aplicación, pues no se trata de señalar cuál ley penal debe aplicarse con exclusión de otra, sino únicamente de hacer racionalmente operativo el mandato de imponer "todas las penas correspondientes a las diversas infracciones". Esto es, no se trata de resolver si una pena se aplica, dejando de imponer la otra, sino únicamente de cómo imponerlas todas, si simultánea o sucesivamente y, en este último caso, cuál imponer primero y cuál después.

18 Véase al respecto MATUS, Jean Pierre, "Dos problemas de aplicación retroactiva de la ley penal favorable en el derecho y la justicia de Chile", Revista de Derecho Penal (España), n 19 (2006), pp. 5998. Estas especulaciones sí tienen importancia, en cambio, tratándose del problema de elegir cuál régimen concursal es más favorable al condenado, si el del art. $74 \mathrm{CP}$ o el del art. $351 \mathrm{CPP}$, como veremos más adelante. 


\section{Reiteración del delitos del art. 351 CPP}

\subsection{Presupuestos de aplicación}

Como señalamos en el apartado anterior, la reiteración de delitos del art. 351 CPP es un caso especial de la regla concursal general y subsidiaria contemplada en el art. $74 \mathrm{CP}$, cuyos presupuestos de aplicación son tres: a) los exigidos para la aplicación de la regla concursal del art. $74 \mathrm{CP}$ (que se trate de un mismo imputado que ha cometido dos o más delitos y no ha sido condenado por alguno de ellos previamente) ; b) que estemos ante un caso de reiteración de delitos de una misma especie, y c) que la pena resultante de aplicar la regulación específica que contempla, sea "menor" que la que resultaría de aplicar las reglas del art. $74 \mathrm{CP}$.

Materialmente, por tanto, lo que determina hipotéticamente el ámbito de aplicación de las reglas penológicas de este art. $351 \mathrm{CPP}$, es la constatación de enfrentarnos ante un supuesto de reiteración de delitos de la misma especie.

Sobre qué ha de entenderse por crímenes y simples delitos de una misma especie, la ley señala que son aquellos "que afectaren al mismo bien jurídico".

Luego, surge la interrogante acerca de qué ha de entenderse por "delitos de la misma especie", esto es, "los que afectaren al mismo bien jurídico".

Lamentablemente, y seguro teniendo en consideración la opinión de que esta regla del art. 351 CPP, "en rigor, debiera estar incardinada en el Código penal", ${ }^{19}$ los comentaristas del CPP $2000,{ }^{20}$ y la doctrina procesal penal actual ${ }^{21}$ se limitan a la trascripción del texto, sin ofrecer orientaciones acerca de su interpretación.

En la historia de la legislación nada se nos dice al respecto, salvo que al suprimirse la guía que ofrecía el antiguo art. 509 CPP (1906) se pretende evitar los problemas interpretativos que originaba, al ordenar considerar de "la misma especie" los delitos contemplados en el mismo

19 HORVITZ, Ma Inés; López, Julián, Derecho Procesal Penal Chileno, t. II, Santiago. Ed. Jurídica de Chile, 2004, p. 344s.

20 CERDA, Rodrigo; HERMOSIlla, Francisco, El Código Procesal Penal, Comentarios, Concordancias, Jurisprudencia, Santiago: Librotecnia: 2003, p. 343.

21 CERDA, Rodrigo, Manual del Nuevo Sistema de Justicia Criminal, Santiago: Librotecnia, 2005, p. 430; CHAHUÁn, Sabas, Manual del Nuevo Procedimiento Penal, $2^{a}$ ed., Santiago: LexisNexis, 2002, p. 346; CORREA , Jorge, Curso de Derecho Procesal Penal, Santiago: Ed. Jurídicas de Santiago, ca. 2004, p. 234; LLANOS, Leopoldo, Sintesis del Nuevo Procedimiento Penal, Santiago: Ed. Jurídicas de Santiago, ca. 2003, p. 128. 
Título del Código Penal o en una misma ley especial, el que habría sido "unánimemente" criticado por la doctrina. ${ }^{22}$

No obstante, lo que la doctrina criticaba del tenor del artículo 509 CP no era una supuesta "dificultad interpretativa", pues su tenor era suficientemente claro, sino ciertas consecuencias indeseables del mismo, esto es, en palabras de CURY, se trataba de una solución "clara pero infortunada", pues llevaba, por ejemplo, a considerar "de la misma especie" el hurto y el robo con homicidio, pero no éste con el homicidio. ${ }^{23}$

Sin embargo, respecto al art. $351 \mathrm{CPP}$, ahora CURY señala que su redacción "si bien se orienta a la solución correcta es incompleta", remitiéndonos precisamente las dificultades que la interpretación "delitos de la misma especie" ha tenido en relación con la agravante de reincidencia propia específica, donde declara que el mayor de los problemas se suscita en torno a los delitos pluriofensivos, que denomina "plurisubsistentes", donde "es prácticamente imposible ofrecer una solución". ${ }^{24}$

Luego, parafraseando a CURY, la solución legal que aquí se ofrece, aunque bienintencionada, no es clara ni afortunada, pues basta revisar la contradictoria jurisprudencia producida en torno a la interpretación del art. $12 \mathrm{~N}^{\mathrm{o}} 16$, para constatar que, salvo en los casos de identidad de norma infringida (como en los casos comunes de reiteración de abusos sexuales) o de que estemos en presencia de claros supuestos de comisión de delitos que son figuras especiales de otros generales concurrentes (como en las diversas figuras de hurtos o falsificaciones), ${ }^{25}$ la aplicación

22 En el Senado de la República se suprimió, "para evitar problemas de interpetación”, la referencia del proyecto original que, junto a la idea del "mismo bien jurídico", agregaba la posibilidad de considerar como delitos de la misma especie los comprendidos en un mismo título del Código o en una misma ley especial (PFEFFER, Emilio, Código Procesal Penal Anotado y Concordado, $2^{a}$ ed., Santiago: Ed. Jurídica de Chile, 2006, p. 275).

23 CURY, Enrique, Derecho Penal, Parte General, t. II, Santiago: Ed. Jurídica de Chile, 1985, p. 274. Allí se menciona otros ejemplos de desafortunadas consecuencias de la regulación anterior, que llevaba a considerar «delitos de la misma especie», por ejemplo, el aborto (art. 342), la suposición de parto (art. 353) y la violación (art. 361); o el parricidio (art. 390) y las calumnias (art. 412), etc.

24 CURY, Derecho Penal, cit. nota al pie n ${ }^{\circ} 6$, pp. 662 y 512 ,

25 La interpretación que aquí se ofrece es similar a la que los integrantes de la Comisión Revisora del Proyecto de CPP de 1906 ofrecían para la interpretación del art. 537 CPP (1906), que años después pasaría a ser el inciso primero del art. 509 CPP (1906), y que al momento de su promulgación no contemplaba una regla acerca de qué habría de entenderse por "delitos de la misma especie". En dicha Comisión, a petición del Sr. Vergara, se discutió la necesidad de "que se determine con toda claridad el alcance de este artículo en cuanto se refiere a las diversas infracciones estimadas como un solo delito", agregando que "él entiende que se ha querido evitar las condenas de ochenta o más años impuestas en casos semejantes a los del Notario de Peumo que se condenó a una pena de más de ochenta años, estimando como un delito separado cada infracción de la ley cometida por dicho funcionario en el otorgamiento de escrituras públicas"; sin embargo, "el señor Presidente estima perfectamente claro el artículo y se refiere, sin duda, no sólo a los casos a que alude el señor Vergara sino también al de reiteración de todo simple delito, como el de hurto, por ejemplo" (LAZO, Santiago, Código de Procedimiento Penal, Orígenes, Concordancias, Jurisprudencia, Santiago: Ed. Poblete Cruzat Hnos., 1917, p. 363s.). 
Proposiciones respecto de las cuestiones no resueltas por la Ley $\mathrm{N}^{\mathrm{o}} 20.084$

en materia de acumulación y orden de cumplimiento de las penas

de esta regla, que no contiene una definición de bien jurídico operativa, producirá diversas interpretaciones, particularmente por el hecho de que muchos delitos no protegen "un" único bien jurídico, sino varios y que, aunque se de el caso de dos o más delitos que protejan "un" mismo bien jurídico, nada impide que cada uno de ellos proteja o no, además, otros bienes jurídicos. Para estos casos, también podría ser posible extender la aplicación de este artículo a los supuestos en que, existiendo delitos que afecten más de "un mismo" bien jurídico, al menos tengan en común la protección de "un mismo" bien jurídico de entre todos los afectados, como sería el caso de reiteración de delitos contra la propiedad (hurtos y robos) ${ }^{26}$ o incluso, entre robos violentos con lesiones y homicidios, según los casos, siendo aquí el "mismo bien jurídico" protegido la vida y la salud de las personas, y no la propiedad.

\subsection{Tratamiento penal de la reiteración de delitos: la regla de la acumulación jurídica o exasperación}

Determinado que se trata de reiteración de delitos de la misma especie, el art. $351 \mathrm{CPP}$ establece dos reglas que permiten resolver el concurso de penas concurrentes con una regla que supone la imposición de una pena diferente a la determinada para cada delito aisladamente, en la que se "acumulan jurídicamente" todas ellas, y que supone, en principio, una suerte de agravación (exasperación) que no alcanzaría, al menos teóricamente, a la intensidad de la que resultaría de la aplicación de las reglas concursales generales. ${ }^{27}$

26 Esta es, por lo demás, respecto a todos los delitos contra la propiedad, la tendencia mayoritaria de la jurisprudencia recopilada por ETCHEBERRY, Jurisprudencia, cit. nota al pie no 10, $t$. I, pp. 405-413 y $t$. $I V$, p. 146 , dentro del contexto de la agravante de reincidencia propia específica. También parece ser la dominante en la jurisprudencia actual, según las sentencias recopiladas por CERDA, Rodrigo; y HERMOSILLA, Franciso, Código Penal, Jurisprudencia en el Nuevo Sistema de Justicia Criminal, Santiago: Librotecnia, 2004, pp. 85-89, aunque hay alguno que incorpora un requisito adicional a la identidad del bien jurídico para considerar los hechos como de "una misma especie", para los efectos del art. 12 n 16 CP, a saber, la identidad en los móviles del hecho (p. 88).

27 FONTECILLA, Rafael, Concursos de delincuentes, de delitos y de leyes penales y sus principales problemas jurídicos, Santiago: Ed. Jurídica de Chile, 1956, p. 80, distingue los regímenes de ambas reglas, indénticas en el antiguo art. 509 CPP (1906) afirmando que en la primera estaríamos ante un sistema ce "cúmulo jurídico" y, en la segunda, ante uno "progresivo". La distinción es pertinente si se estima que, efectivamente, en el primer caso se puedan "sumar las cuantías", lo cual nosotros rechazamos, como se verá enseguida en el texto. A los argumentos que allí se exponen cabe agregar que la regla de la "suma de las cuantías" para el caso común, el del hurto en ciertas circunstancias (cometido en "un mismo lugar" o contra "una misma persona"), está establecida así expresamente en una regla especial (la del art. $451 \mathrm{CP}$ ), que no está contenida en el actual art. $351 \mathrm{CPP}$, pudiendo el legislador perfectamente haberla copiado, de estimarla adecuada. Es, por lo tanto, posible afirmar que si así no se ha hecho en las numerosas oportunidades tenidas al efecto, es porque no se estima que dichas reglas tengan el mismo contenido normativo. FONTECILLA emplea la distinción, además, para hacer aplicable sólo al segundo caso la excepción de volver a la regla general del art. $74 \mathrm{CP}$, en caso de ser éste más favorable al condenado, al ofrecer una pena menor. Sin embargo, no se ve razón alguna para ello, como sí es posible apreciar frente a las situaciones excepcionales del art. $451 \mathrm{CP}$, donde la unidad de víctima o su pluralidad en un contexto de unidad especial, parecen justificar la suma de las cuantías del hurto, considerándolo un único delito. 
La primera regla se refiere al caso en que las diversas infracciones se pueden "estimar como un solo delito". La regla penológica en este primer supuesto es estimar el hecho como un solo delito y aumentar la pena en uno o dos grados. Nuestra doctrina dominante considera como "caso característico" de este supuesto, "el de aquellos delitos en que la penalidad se determina por la cuantía o el monto (de lo hurtado, de lo estafado, de lo malversado, etc.)"28 y, por lo tanto, se podría hacer la suma de cuantías para determinar la pena aplicable ${ }^{29}$, lo que es rechazado - con razón- por GARRIDO, para quien esta suma de cuantías sería una aplicación analógica contra el reo de lo dispuesto en el art. $451 \mathrm{CP}$, pues produciría, en ciertos casos, una agravación mayor que la de aplicar la regla siguiente, propone que en este supuesto se incluyan solamente los casos de reiteración del mismo delito "(todos son hurtos de cuantías análogas, o lesiones, u homicidios simples o siendo iguales alcanzan distintos niveles de ejecución)", ${ }^{30}$ a los cuales se podrían agregar los cada vez más frecuentes de abusos sexuales. ${ }^{31}$

En cambio, si las diversas infracciones reiteradas no pueden considerarse como un único delito, supuesto donde la doctrina dominante debiera incluir el caso obvio de la reiteración del mismo delito, se aplica la pena de aquélla que "considerada aisladamente, con las circunstancias del caso, tenga asignada pena mayor, aumentada en uno o dos grados". Conforme a lo señalado en el párrafo anterior, nosotros estimamos que aquí deben comprenderse los casos en que, lesionándose un mismo bien jurídico, los delitos sean de diferente naturaleza (por ej.: hurtos y robo con fuerza de cosas que se encuentran sobre bienes nacionales de uso público). GARRIDO extiende esta regla a los supuestos en que la reiteración comprende delitos pluriofensivos "(robos y hurtos, injuria y homicidio)", ${ }^{32}$ interpretación que, aunque probablemente inspirada al pie forzado del tenor literal del antiguo inciso tercero del 509 CPP 1906, puede mantenerse hoy en día si se estima que se refiere a los casos en que los delitos pluriofensivos tienen al menos "un mismo" bien jurídico protegido en común.

En ambos casos, el aumento de grado es obligatorio y debe hacerse a partir de la pena

ETCHEBERRY, Derecho Penal, t. II, cit. en nota al pie no 4, p. 117.

NOVOA, Curso, t. II, cit. nota al pie $\mathrm{n}^{\circ} 6$, p. 227. Esta es, por lo demás, la expresa voluntad de la mayoría de la Comisión Revisora del Código de Procedimiento Penal de 1906 (LAZO, cit. nota no 26, p. 364)

GARRIDO, Derecho Penal, t. II., cit. en nota al pie $\mathrm{n}^{\circ} 11$, p. 346. No obstante, debo reconocer que en nuestras obras anteriores, citadas en la nota al pie $\mathrm{n}^{\circ} 2$, no se habían tomado suficientemente en cuenta los buenos argumentos de GARRIDO, y se seguía sin más la doctrina tradicional chilena.

Así también la SCA Pedro Aguirre Cerda (1981), RDJ LXXVIII, 4-67, cit. por ETCHEBERRY, Jurisprudencia, $t$. $I V$, cit. nota al pie $\mathrm{n}^{\circ} 10$, p. 206, quien, sin embargo, se manifiesta en contra de esta solución.

GARRIDO, Derecho Penal, t. II., cit. en nota al pie n 11, p. 346. 
Proposiciones respecto de las cuestiones no resueltas por la Ley $\mathrm{N}^{\mathrm{o}} 20.084$

en materia de acumulación y orden de cumplimiento de las penas

concreta determinada, aplicando las circunstancias que sean del caso. ${ }^{33}$ Es por ello que, no concurriendo circunstancias que modifiquen un marco penal compuesto de dos o más grados, el aumento puede hacerse a partir del grado mínimo de éstos, asumiendo que éste corresponde a la pena determinada. ${ }^{34}$ Por otra parte, aunque la cuantía del aumento es facultativa, advierte NOVOA, con razón, que "a mayor número de delitos que integren la reiteración, mayor tendrá que ser, por lo general, el aumento de grados; otra cosa sería burlar la voluntad legislativa" ${ }^{35}$.

Además, ambas reglas operan sobre la idea de que al menos uno de los delitos que se comete contempla penas que pueden graduarse, sus grados se encuentran en alguna escala determinada y es posible el aumento de al menos un grado de ellas. Por lo tanto, no son aplicables a los casos en que todos los delitos concurrentes sólo contemplan penas que carecen de grados (como la multa); o uno de ellos merece ser castigado, en concreto, con una pena indivisible no susceptible de agravación en grado (como el presidio perpetuo calificado, grado $1^{\circ}$ de la Escala ${ }^{\circ} 1$ del Art. 59), para los cuales rige la regla general del art. 74 CP: imposición simultánea de las penas (penas que carecen de grados), o sucesiva (penas indivisibles no susceptibles de agravación). ${ }^{36}$

\subsection{Límite de la aplicación del art. 351 CPP: el caso en que de aplicar el art. 74 CP resulte una "pena menor"}

Salvo los dos últimos supuestos mencionados en el párrafo anterior, la determinación de la pena aplicable en concreto en conformidad a las reglas penológicas del art. $351 \mathrm{CPP}$ es obligatoria en todos los casos de reiteración de delitos de la misma especie.

Sin embargo, el art. 351 CPP plantea la posibilidad de no imponer, en definitiva, la pena así determinada, sino las que resulten de la aplicación de las reglas generales del art. $74 \mathrm{CP}$, cuando ellas supongan una "pena menor" para el condenado.

33 Con todo, como señala ETCHEBERRY, Jurisprudencia, $t$. IV, cit. en nota al pie $\mathrm{n}^{\text {o }} 10$, p. 207s., hay jurisprudencia contradictoria, sobre todo para el caso en que los hechos puedan considerarse "como un solo delito". Sin embargo, el procedimiento contrario, esto es, elevar la pena a partir del marco establecido en el tipo penal, impide una adecuada comparación de este sistema con las reglas del art. $74 \mathrm{CP}$, cuando se requiere establecer cuál de ellos supone una "pena menor", pues se estarían comparando penas abstractas con concretas, lo que fuerza un poco la lógica y hace perder el sentido del art. 351, que es ofrecer un sistema penológico más benigno que el de la regla general.

34 Como el cálculo se hace «con las circunstancias del caso», se cumple con la ley si sólo se toma en cuenta el grado mínimo de la pena mayor, SCS 16.07.1946, RCP IX, 209.

35 NOVOA, Curso, $t$. II, cit. nota al pie $\mathrm{n}^{\circ} 6$, p. 227.

36 De otro modo, en este último caso, se produciría la extraña situación de que quien ha cometido un crimen que, con todas las circunstancias del caso, merece pena de presidio perpetuo calificado, quedaría "impune" por el resto de los delitos que cometiese antes de ser procesado y condenado por el primero. Esta situación estaba antes detalladamente regulada en el hoy derogado inc. $3^{\circ}$ del art. 74 , para el caso que se impusiere la pena de muerte: el resto de las penas también debían imponerse, quedando únicamente su ejecución sujeta a la condición de que la de muerte se ejecutase efectivamente. 
Por lo tanto, también en todos los casos de reiteración de delitos de la misma especie ha de hacerse la determinación de las penas aplicables en concreto conforme a lo dispuesto en el art. $74 \mathrm{CP}$.

Luego, ha de comparase la pena única concreta resultante de las reglas del art. $351 \mathrm{CPP}$ con la "suma hipotética" de las concretas penas resultantes de la aplicación del art. 74 CP, para determinar, según el texto de la ley, cuál de ellas es la "pena menor". ${ }^{37}$

Esta comparación, dado que el art. $351 \mathrm{CP}$ utiliza determinadamente la expresión "pena menor", sólo puede referirse a una comparación cuantitativa de la duración de las penas resultantes en concreto. En este sentido, el artículo no autoriza una comparación cualitativa acerca de la gravedad de las penas concurrentes, ${ }^{38}$ sino únicamente una cuantitativa, en relación a su duración temporal.

La operación es relativamente sencilla en el caso de tratarse de delitos que merecen únicamente penas temporales privativas de libertad: se "suma" hipotéticamente la duración de cada una de las penas posibles de imponer según el art. 74 CP y se compara con la resultante de la aplicación del art. $351 \mathrm{CP}$; el régimen concursal que suponga la imposición de una "pena menor" en duración temporal es el que se aplicará en definitiva.

Tampoco genera problemas la comparación entre penas compuestas de privativas de libertad y otras que puedan imponerse simultáneamente (pecuniarias y privativas de derechos), pues si el propósito de las reglas relativas a la reiteración es evitar la imposición de una "pena de presidio perpetuo, aunque con otro nombre", 39 resulta más o menos claro que la comparación sólo ha de hacerse entre la duración de las penas privativas de libertad resultantes en concreto.

37 Aunque la sencillez de este procedimiento parece acorde con el sentido de la ley y el principio de legalidad (de no existir reglas concursales, esto es lo que habría que hacer siempre: calcular las penas que corresponden en concreto a cada delito e imponerlas conjuntamente), y aún con el de igualdad ante la ley (ese es el procedimiento en casos de reincidencia: cada delito se castiga con su pena, determinada en concreto), el análisis jurisprudencial de ETCHEBERRY, Jurisprudencia, t. II, pp. 101-110, muestra las vacilaciones y divergencias en la aplicación de estas reglas por parte de nuestros tribunales, las cuales parecen siempre guiadas por el interés de imponer una pena menor o mayor, según los casos (por lo general -pero no siempre así-: pena menor para reiteración de delitos contra la propiedad, pena mayor en caso de reiteración de delitos contra las personas), que la llevan a veces sí y a veces no a hacer cálculos y comparaciones en base a la pena abstracta, particularmente en el caso de que los hechos puedan estimar "un solo delito". Lamentablemente, un proceder de esta manera no es susceptible de reconducir a directrices racionales para casos futuros y sólo cabe señalar que, así como es posible errar en la interpretación, también lo es que el interés de benignidad o severidad lleve a combinaciones en la aplicación de las reglas legales imposibles de sistematizar y por lo tanto, que quedan fuera de un análisis racional.

38 Por lo tanto, tampoco caben aquí las disquisiciones acerca de cuál es la "pena más grave" o la "menos rigurosa", propias de la teoría de la aplicación de la ley en el tiempo (ver nota al pie n 19). 
Proposiciones respecto de las cuestiones no resueltas por la Ley $\mathrm{N}^{\mathrm{o}} 20.084$

en materia de acumulación y orden de cumplimiento de las penas

En principio, y dado que el art. 74 CP ordena también la acumulación y aplicación "sucesiva" de las penas privativas y restrictivas de libertad, también parece posible hacer la comparación cuantitativa que ordena el art. $351 \mathrm{CPP}$, entre la suma de la duración de todas ellas y la que resulte de la pena única determinada conforme al artículo $451 \mathrm{CP}$ (que también podría ser compuesta, en aplicación de la regla del art. $61,4^{\mathrm{a}} \mathrm{CP}^{40}$ ). La pena "menor" sería, en este caso la de menor duración temporal total, que es el único parámetro cuantificable que permitiría la comparación de esta clase de penas, para afirmar que una es "menor" que la otra.

En cambio, si los delitos concurrentes sólo tienen asignadas penas privativas de derechos graduables (o éstas conjuntamente con otras no graduables o con otras pecuniarias), que pueden cumplirse simultáneamente, la comparación resulta innecesaria, dado que la disposición del art. 351 CPP siempre produciría un efecto de mayor duración temporal.

\section{Ley 18.216 y el régimen concursal}

Aunque su propósito de evitar la imposición de penas cortas privativas de libertad, facilitando la reintegración social de los primerizos en el delito, así como la literalidad de los artículos de la Ley $\mathrm{N}^{\mathrm{o}} 18.216$, parecen restringir su potencial aplicación a los casos en que se impone una pena por un único hecho punible, ${ }^{41}$ esto es, a la delincuencia ocasional y no a la habitual o reiterada, ${ }^{42}$ la práctica de nuestros tribunales parece no ir en esa dirección,

40 Al respecto, ver MATUS, Jean Pierre; WEEZEL, Alex van, “Artículos 50 a 73”, en: POLITOFF/ ORTIZ/MATUS, Texto y Comentario, cit. en nota al pie $n^{\circ} 2$, pp. 323-382, p. 345s.)

$41 \quad$ Allí se que faculta al Tribunal para decretar la suspensión de la ejecución de "la pena privativa o restrictiva de libertad que imponga la sentencia al condenado", reemplazándola por la remisión condicional "si los antecedentes del condenado, su conducta anterior y posterior al hecho punible y la naturaleza, modalidades y móviles determinantes del delito permiten presumir que no volverá a delinquir" (art. $4^{\circ}$, c)); la reclusión nocturna, "si los antecedentes del condenado, su conducta anterior y posterior al hecho punible y la naturaleza, modalidades y móviles determinantes del delito permiten presumir que la medida de reclusión nocturna lo disuará de cometer nuevos delitos" (art. $\left.8^{\circ}, \mathrm{c}\right)$ ); o la libertad vigilada, "si los antecedentes del condenado, su conducta anterior y posterior al hecho punible y la naturaleza, modalidades y móviles determinantes del delito permiten presumir que no volverá a delinquir" no volverá a delinquir" $\left(\right.$ art. $\left.\left.4^{\circ}, \mathrm{c}\right)\right)$.

42 Aunque FONTECILLA, Concursos, p. 82, critica la regulación concursal proveniente del sistema "clásico", que se traduciría en "el objetivismo más crudo", lo hace no porque la reiteración no debe tomarse en cuenta, sino porque la regulación concursal "clásica" no toma en cuenta adecuadamente el problema de la delincuencia habitual, produciendo resultados "manifiestamente absurdos", si se miran desde el punto de vista de la necesidad de tratamiento del sujeto que delinque de este modo: "así, el cúmulo material es inaplicable porque muchas veces las penas no alcanzarían a cumplirse durante la vida del condenado", agregando: "basta con imaginar la ridiculez de una pena de doscientos años de presidio"; y, por otra parte, "el sistema de la absorción deja en la impunidad el delito menor y el cúmulo jurídico no pasa de ser una combinación artificiosa entre la intensidad y la duración de la pena". Estas críticas al sistema concursal legal, desde el punto de vista de la peligrosidad del agente manifestada en la reiteración de delitos, no pueden justificar llegar a hacer caso omiso de ésta y de aquella y, sencillamente, por el solo albur de aplicar una regla como la del art. $351 \mathrm{CPP}$ o la "unificación de penas" correspondientes al art. $74 \mathrm{CP}$, hacer "como si" se hubiese cometido "un único delito" y no se esté frente al caso de una reiteración de delitos cometidos por un mismo sujeto. 
conformándose básicamente con el cumplimiento de los requisitos objetivos que dichas disposiciones establecen para la concesión de los mencionados beneficios, esto es, la duración de la pena impuesta, a saber, si esta no excede de tres, dos o cinco años de privación o restricción de libertad, según los casos.

Así, para el caso de imponer penas conforme al sistema del art. $351 \mathrm{CP}$, la duración de la pena única que de éste resulta, se contrasta con los requisitos objetivos antes mencionados; y en los casos del art. $74 \mathrm{CP}$, ello se verifica mediante la "suma hipotética" de todas las penas a imponer. ${ }^{43}$

De este modo, el sistema de suspensión y sustitución de penas que establece la Ley $\mathrm{N}^{\mathrm{o}}$ 18.216 no produce efecto alguno en el régimen concursal aplicable, sino al revés: la duración de la pena única determinada según el art. 351 CPP, o de la suma de las penas impuestas según lo dispone el art. 74, es lo que determina la concesión de alguno de los beneficios de dicho cuerpo legal.

\section{La mal llamada "unificación de penas" del art. 164 COT}

Dado que en el Proceso Penal vigente no existe la obligación de acumular los autos que se imponía en el CPP 1906, bajo la regla general del inciso $1^{\circ}$ de su ya derogado art. 160, según la cual "el culpable de diversos delitos" debía "ser juzgado por todos ellos en un solo proceso", quedando la agrupación o separación de investigaciones y procesos como una facultad discrecional del Ministerio Público, regida bajo el principio de la conveniencia ${ }^{44}$ (aunque sometida a revisión judicial, en interés de una adecuada defensa del imputado y para evitar "provocar decisiones contradictorias" ${ }^{45}$, "la necesidad de una regulación" que tenga establezca "la manera en que el tribunal debe determinar la pena en los casos de concurso de delitos o de reiteración, cuando los procesos correspondientes a los diferentes delitos han sido 'desacumulados", ${ }^{46}$ parece estar fuera de discusión.

Y así, aunque el texto del actual art. 164 COT no utiliza la expresión “unificación de las

43 Ver al respecto las sentencias citadas por CERDA, Rodrigo, "Institución de unificación de penas contemplada en el artículo 164 del Código Orgánico de Tribunales”, Revista de la Justicia Penal, n 2 (2008), pp. 187-208, donde se puede apreciar que la única consideración para negar en la mayor parte de los casos el beneficio solicitado es la cuantía de la pena impuesta en definitiva, sin hacerse cuestión del problema implícito de la reiteración, como muestra de una conducta difícilmente reconducible a los presupuestos de la Ley $\mathrm{N}^{\mathrm{o}} 18.216$.

44 CHAHUÁN, Manual, cit. nota al pie no 22, p. 188.

45 HORVITZ / LÓPEZ, Derecho Procesal Penal, cit. nota al pie n ${ }^{\circ} 20$, p. 53s.

46 WEEZEL, Alex van, "Unificación de las penas: la regla del artículo 160 inciso $2^{\text {a }}$ del Código Orgánico de Tribunales", Revista de Derecho de la Universidad de Concepción, $\mathrm{n}^{\mathrm{o}} 207$ (2000), pp. 55-58, p. 55. 
Proposiciones respecto de las cuestiones no resueltas por la Ley $\mathrm{N}^{\mathrm{o}} 20.084$

en materia de acumulación y orden de cumplimiento de las penas

penas", su propósito no es sustancialmente diferente al del antiguo inciso $2^{\circ}$ del art. 160 COT, pues sus presupuestos son similares: la imposición en procesos diferentes de dos o más condenas a un mismo imputado, sin que entre el momento de realización de los delitos respectivos hubiese mediado una sentencia condenatoria, siempre que fuese posible la apreciación de una regla concursal (concurso ideal, medial o reiteración) que en concreto resulte más beneficiosa para el reo:47 y también son similares sus consecuencias: "regular la pena de modo tal que el conjunto de penas no pueda exceder de aquella que hubiere correspondido de haberse juzgado conjuntamente los delitos". ${ }^{48}$

Sin embargo, donde comienzan las diferencias con la anterior regulación es en la forma y el modo en que este propósito legislativo ha de cumplirse.

En efecto, en primer lugar, ya no existe una obligación general de hacer la "unificación de penas" en el "último" de los fallos, pues es relativamente claro que cuando la imposición "por separado" de las distintas condenas no suponga la imposición de consecuencias penales más graves para el imputado, éste no estará interesado en una "unificación” perjudicial ni es ese el espíritu del sistema concursal general ni lo que manda el actual art. 164 COT. $^{49}$

En segundo término, ya no se requiere esperar a la "última" de las sentencias para proceder, en caso que corresponda, con la unificación, sino que ésta es ordenada consecuencialmente, de manera que en cada sentencia "posterior" el Tribunal competente debe tomar en cuenta la dictada anteriormente. Esto significa que a partir de la segunda sentencia condenatoria contra un imputado por un hecho que pudo haberse juzgado en conjunto con el primero, el Tribunal competente para este segundo proceso debe tomar en cuenta lo resuelto en el primero de ellos. Y así sucesivamente.

47 Por lo tanto, no corresponde ya "sumar las penas" en casos del art. 74, como mandaba el derogado art. 160 COT (WEEZEL, "Unificación”, cit. en nota anterior, p. 56), pues ese efecto se encuentra ya determinado por la sola existencia de diversas sentencias de carácter obligatorio, esto es, de "penar por separado" (CUERDA, Concurso, cit. en nota al pie $\mathrm{n}^{\circ} 9, \mathrm{pp} .49 \mathrm{ss}$ ) sino únicamente determinar si concurre un supuesto de concurso ideal, medial o uno de reiteración, que eventualmente conllevarían a la imposición de una pena menos rigurosa. Como ya hemos visto que los dos primeros casos no tienen un ámbito importante de aplicación práctica en Chile (nota al pie $\mathrm{n}^{\circ} 4$ ), la cuestión se reduce, como se me ha planteado en las consultas, a saber si estamos ante un caso de reiteración de delitos del art. $351 \mathrm{CP}$, pero sólo si la aplicación de su regla penológica resulte más favorable al condenado.

48 Para la historia de la legislación, véase CERDA, "Unificación”, cit. nota al pie nº 27, pp. 187-189.

49 Por eso es que, con sano criterio, el inciso segundo de esta disposición ha concedido al condenado (y no al Ministerio Público) la facultad de solicitar la modificación del fallo "posterior", como una forma de compensar, a través de la actividad del más interesado en ello, una eventual falta de celo de los Tribunales en realizar esta modificación. Es obvio, además, que en un sistema acusatorio, con Defensoría Penal Pública, bastaría haber dejado únicamente a petición del condenado la activación de este incidente de "unificación de penas". 
Y en cuanto al modo, la "unificación" no resulta ser más "el cálculo de la pena unificada correspondiente", ni se requiere la dictación de una resolución que "unifique" las condenas anteriores y que deba "añadirse" a la última de ellas, ${ }^{50}$ sino que supone un proceso en tres etapas: a) el cálculo de la pena en concreto, esto es, considerando todas las circunstancias del caso que deban considerarse, que corresponde al hecho que se juzga de manera "posterior"; b) el cálculo hipotético de las pena en concreto correspondiente al conjunto de los delitos, si hubiesen sido juzgados conjuntamente, cuando aparezca como posible la aplicación un régimen concursal más favorable al condenado que el del art. $74 \mathrm{CP}$; y c) el cálculo de la nueva pena a imponer efectivamente en el proceso "posterior", "de modo tal que el conjunto de penas no pueda exceder de aquella que hubiere correspondido de haberse juzgado conjuntamente los delitos". 51

Por lo tanto, más que un procedimiento de "unificación de penas", lo que el art. 164 COT establece, para cumplir similar finalidad, es un procedimiento de "modificación de la condena posterior", para adecuarla a la que hubiese correspondido de haberse juzgado conjuntamente los hechos, siempre que de este procedimiento resulte la aplicación de un régimen concursal más favorable penológicamente para al condenado.

\subsection{Aplicación de la regla penológica del art. 74 CP, en el contexto de la mal llamada unificación de penas del art. 164 COT}

Aunque aparentemente el problema de determinar el orden de aplicación de las "todas las penas" impuestas a un condenado parece vinculado únicamente a la regla del art. $74 \mathrm{CP}$, este problema es, en principio, independiente del hecho de que esas penas se impongan simultáneamente o no en un mismo proceso, lo que se puede apreciar con claridad en el caso de que distintas sentencias se vayan imponiendo sucesivamente en el tiempo, el cual es precisamente el presupuesto del art. 164 COT.

Como ya dijimos, esta disposición no faculta al tribunal a "unificar las penas" impuestas, sino solamente a modificar la última de ellas, y sólo en caso de que con ello se exceda de la pena

50 WEEZEL, "Unificación”, cit. nota al pie n 46, p. 58.

$51 \quad$ Y así puede apreciarse, por ejemplo, en la sentencia de 6.12.2006 del Tribunal Oral en lo Penal de Copiapó, causa RIT 127-2004, donde, luego de un "raciocinio hipotético, para determinar la pena concreta a aplicar, que consiste en determinar la sanción que habrían tenido los condenados en el caso hipotético de haberse acumulado las causas", los sentenciadores "fueron del parecer que a los sentenciados les hubiese resultado más favorable aplicar lo dispuesto en el artículo 451 del Código Procesal Penal, por sobre lo establecido en el artículo 74 del Código Penal"; y, por lo tanto, "se estimó pertinente y ajustado a derecho rebajar la pena contenida en la presente causa, a fin de ajustarla a aquella pena que hubiere correspondido en caso de existir la referida reiteración" (en: Boletín de Jurisprudencia, Departamento de Estudios de la Defensoría Nacional, nº 1 (2007), p. 133). 
Proposiciones respecto de las cuestiones no resueltas por la Ley $\mathrm{N}^{\mathrm{o}} 20.084$

en materia de acumulación y orden de cumplimiento de las penas

prevista por un régimen concursal más favorable. A contrario sensu, en caso de que del régimen penal del art. 74 resulte una "pena menor" que del de la reiteración del art. $351 \mathrm{CP}$, el Tribunal "posterior" debe limitarse a imponer la pena que corresponda por el hecho que enjuicia, no existiendo la posibilidad legal de dictar una nueva resolución que "sume las penas" o cree una "pena conjunta", mezclando unas y otras. ${ }^{52}$

De este modo, dado que, materialmente, la regla del inc. $2^{\circ}$ del Art. 74 resuelve el concurso de penas que de este modo se produce, ordenando la aplicación simultánea de todos las penas, o sucesiva, cuando ello no fuere posible o resulte ilusorio el cumplimiento de alguna, ${ }^{53}$ el único problema normativo que se produce es la determinación formal del orden en que se ejecutarán todas las penas impuestas, pues el art. 164 COT no habilita expresamente al Tribunal "posterior" para resolver la cuestión del orden de aplicación de las penas impuestas.

Sin embargo, este habilitación se encuentra en los arts. 466 a 468 CPP, donde se obliga al Juzgado de Garantía competente decretar "una a una todas las diligencias y comunicaciones que se requieren para dar total cumplimiento al fallo" (art. 468), y, en cuanto al orden de ejecución de su cumplimiento, aunque nada se dice al respecto directamente, dado que el art. 467 obliga a efectuar "la ejecución de las sentencias", "de acuerdo con las normas ... establecidas por el Código Penal”, ello hace obligatorio al Tribunal la aplicación de lo allí dispuesto, particularmente en el inciso segundo de su artículo 74.

Así, si es del caso que sea este mismo Juzgado, el que dicte la sentencia "posterior", le corresponderá, a reglón seguido, decretar el orden de cumplimiento de las penas impuestas, conforme a la regla general del inc. $2^{\circ}$ del art. 74 CP. Y si es otro el Tribunal del fallo "posterior", en caso de que éste no lo haya resuelto incidentalmente y de duda acerca del orden de ejecución de todas las penas impuestas, corresponderá ocurrir ante el Juzgado de Garantía competente para su resolución, conforme a las reglas generales.

\subsection{Aplicación de la regla penológica del art. $351 \mathrm{CP}$, en el contexto de la mal llamada unificación de penas del art. 164 COT}

52 Ya vimos que la obligación de "sumar penas" sí existía en la regulación del art. 160 COT ya derogado, pero ni aún en esa regulación se permitía la creación de una "pena conjunta” o "global” (WEEZEL, "Unificación”, cit. en nota $\mathrm{n}^{\circ}$ ¡Error!Marcador no definido., p. 56)

53 El carácter general de esta disposición se reconoce, también, en el art. $91 \mathrm{CP}$, donde se establece que, en caso de que se delinca durante el cumplimiento de una pena ya impuesta, quienes lo hagan "sufrirán la pena que la ley señala al nuevo crimen o simple delito que cometieren, debiendo cumplir esta condena y la primitiva por el orden que el tribunal prefije en la sentencia, de conformidad con las reglas prescritas en el artículo 74", disposición que no ha sido objeto de crítica por parte de nuestra doctrina, (KÜNSEMÜLLER, Carlos, “Artículos 90 a 92”, en POLITOFF/ORTIZ/MATUS, Texto y Comentario, cit. en nota $n^{\circ} 2$, pp.421-432, p. 426) 
En caso de que el supuesto juzgado por el "tribunal posterior" pueda considerarse un delito de la misma especie que alguno de los juzgados anteriormente y que pudieron haber sido juzgados en un mismo proceso, corresponderá al Tribunal "posterior" realizar las siguientes operaciones:

i) imponer la pena concreta que correspondería al caso que juzga (sin tomar en consideración la circunstancia agravante de la reincidencia, que no podría haberse considerado de juzgarse conjuntamente los hechos);

ii) hacer, hipotéticamente, la regulación de la pena conforme a los reglas del art. $351 \mathrm{CPP}$, antes explicadas;

iii) comparar dicha pena con la suma de la duración de las antes impuestas y de la que resulte del propio hecho que juzga; $y$

iv) si la pena única del art. 351 CPP resulta "menor" que la suma antedicha, reducir la pena concreta ya calculada para el caso que se juzga, de manera que la suma resultante no exceda de la pena única que podría haberse impuesto, de juzgarse todos los hechos conjuntamente. ${ }^{54}$

\subsection{El problema de la aplicación de la ley 18.216 en el contexto de la mal llamada unificación de penas del art. 164 COT.}

Si se toma en serio tanto la finalidad como la literalidad de la Ley $\mathrm{N}^{\circ} 18.216$, podrá apreciarse que, en el contexto del actual art. $164 \mathrm{COT}$, su ámbito de aplicación se restringiría considerablemente.

En efecto, dado que el art. 164 sólo regula la forma cómo debe adecuarse la "sentencia posterior" a la pena que correspondería imponer conforme a las reglas generales y no autoriza ni a modificar las penas antes impuestas ni a "unificar" todas ellas, a partir de la segunda condena no resultaría posible, desde el punto de vista de la simple literalidad de las normas objetivas, conceder en la "sentencia posterior", la remisión condicional o la libertad vigilada a una persona que ya ha sido condenada previamente, y cuyas condenas anteriores no está facultado el tribunal posterior a modificar.

54 Nótese que la ley no exige que se imponga alguna pena por el tribunal "posterior", siendo posible que éste decida no imponer ninguna pena, si al hacerlo se excedería el máximo que pudiese imponerse conforme al art. 351 CPP, como sucedería, por ejemplo, si un tribunal anterior intermedio (posterior a la primera sentencia, pero anterior a la última), ya hubiese hecho tal regulación de modo que el total de las penas impuestas ya hubiese alcanzado al máximo que resultaría de haber aplicado en un solo proceso las reglas del mencionado art. 351 CPP. Este es el caso de la sentencia de 1.10.2005, dictada por el Tribunal Oral en lo Penal de Antofagasta, RIT 138-2005, citada por CERDA, "Unificación", cit. nota al pie n 27, p. $206 \mathrm{~s}$ 
Luego, sólo quedaría la posibilidad de otorgar el beneficio de la reclusión nocturna a quienes fuesen condenados a una pena inferior a dos años y sus condenadas anteriores no excedan en total de esa cantidad.

\section{Concurso de delitos y reiteración frente a la Ley $\mathbf{N}^{\circ} \mathbf{2 0 . 0 8 4}$, sobre Responsabilidad Penal de los Adolescentes}

\subsection{El supuesto básico: unidad de procedimiento, pluralidad de delitos y unidad de la sanción aplicable en conformidad con la Ley $\mathbf{N}^{\circ} \mathbf{2 0 . 0 8 4}$}

De acuerdo a lo dispuesto en la Ley $N^{\circ} 20.084$, la determinación de las sanciones aplicables en definitiva a los menores supone un procedimiento en dos etapas: "primero debe establecerse la duración de la sanción, recurriendo a la extensión temporal de las penas asignadas a los delitos contenidos en el Código Penal, y sólo una vez determinada aquélla puede designarse la naturaleza de la sanción aplicable al caso." ${ }^{55}$

Así, la primera de estas etapas consiste en determinar cuantitativamente la duración de la pena que, conforme a las reglas generales establecidas en el Párrafo 4 del Título III del Libro I del $\mathrm{CP}$, correspondería al hecho, considerando como punto de partida para este procedimiento la "pena asignada al delito", rebajada en un grado (Art. 21 de la Ley $\mathrm{N}^{\mathrm{o}}$ 20.084). A partir de esa rebaja general, deben hacerse el resto de las rebajas o aumentos que correspondan, atendiendo a las etapas de ejecución del delito, los grados de participación en el hecho, las circunstancias atenuantes y agravantes concurrentes y "las reglas de los artículos 74 y 75 del CP relativas a los

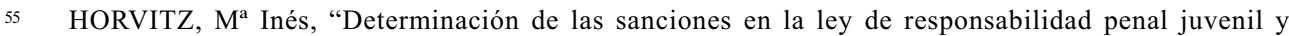
procedimiento aplicable", Revista de Estudios de la Justicia, no 7 (2006), pp. 97-119, p. 102. 
concursos de delitos, complementadas por el artículo 351 del CPP, relativo al concurso material de delitos de la misma especie." 56

Dado que para el cálculo de la pena debe partirse de la rebajada en un grado a la señalada por la ley, en todos los casos el juego de atenuantes y agravantes estará regulado por lo dispuesto en el art. 67 del Código Penal, con independencia de si concurren o no en el caso alteraciones en los grados de desarrollo del delito o de participación en él. Y también es este artículo 67 el que regulará la determinación de la pena en estos casos, ya que en ellos, por regla general, procede una nueva rebaja en uno o dos grados de la pena señalada por la ley al delito. ${ }^{57}$

Finalmente, para los efectos de la duración definitiva de la sanción impuesta, debe considerarse todavía la regla de su artículo 18 que impone un límite temporal absoluto de 10 o 5 años de privación de libertad, según la edad del infractor al momento de la comisión del hecho, esto es, entre 16 y 18 años o entre 14 y 16 años, respectivamente.

56 CERDA, Mónica y CERDA, Rodrigo, Sistema de responsabilidad penal para adolescentes, Santiago: Librotecnia, 2006, pp. 85s. La cita es de la p. 86. Los autores proponen, en atención a la remisión que el art. 22 (hoy 21) de la Ley $\mathrm{N}^{\mathrm{o}} 20.084$ hace a las reglas generales de determinación de la pena en el Código Penal, y de que ellos se declaran "partidarios de la aplicación absoluta, imperativa, preferente y sin excepciones de las reglas de proporcionalidad contenidas en los artículos 51 y 52 del CP", "la derogación, por norma posterior y especial, del artículo 450 inciso $1^{\circ}$ del mismo cuerpo legal”. El argumento no puede aceptarse, pues en ninguna parte de las disposiciones de la Ley $\mathrm{N}^{\mathrm{o}} 20.084$ se hace exclusión de la regla del artículo 55 del Código Penal, comprendido en la remisión general que el art. 21 hace a las reglas de determinación de la pena del Código Penal, que reconoce la posibilidad de que las de los artículos 51 y 52 sean modificadas por el propio legislador al señalar las penas que corresponden a cada delito en particular, habiendo tenido el legislador no sólo oportunidad de hacerlo, sino incluso haberlo hecho con otro artículo de este Título, el 69, que expresamente excluyó en su art. 21 la ley $\mathrm{N}^{\circ}$ 20.084 de las reglas de determinación cuantitativa de la pena para el caso de los hechos juzgados conforme a ella. Tampoco aparece alguna imposibilidad lógica entre este procedimiento común del legislador y las reglas especiales de la Ley $\mathrm{N}^{\mathrm{o}} 20.084$, pues la rebaja en un grado de la pena señalada por la ley bien puede hacerse antes o después de aplicar las reglas del art. 51 y 52, sin que con ello se altere el resultado de sumar grados en la rebaja, y es obvio que dicha rebaja se puede aplicar a la pena señalada por la ley para el autor del delito consumado (art. 50) o el cómplice o encubridor del mismo o el de un delito tentado o frustrado, cuando sea el propio legislador quien señala dicha pena. En definitiva, que la Ley $\mathrm{N}^{\mathrm{o}} 20.084$ haga una remisión a las reglas generales de determinación de la pena del Código Penal, no agrega ningún argumento a la cuestión ya discutida en sede de derecho penal de adultos, acerca de si el art. 450 inc. $1^{\circ}$ del Código Penal se adecua o no a nuestra Constitución o los principios generales del derecho, resuelta favorablemente por nuestra Corte Suprema en el mismo sentido que el que nosotros proponemos (POLITOFF/ MATUS / RAMÍREZ, Lecciones, Parte Especial, cit. nota al pie no 8, p. 380, con referencias a la jurisprudencia de la Corte Suprema en el mismo sentido, y los textos de WEEZEL, Alex van, “¿Es inconstitucional el artículo 450, inciso primero, del Código Penal?, comentario a la SCA Santiago 15.11.200", Revista Chilena de Derecho, vol. 28 No 1 (2001), pp. 191-194 y BASCUÑ́́N R., Antonio, "Nota a la SCS 25.08.2003, Revista de Derecho de la U. Adolfo Ibáñez, no 1 (2004), pp. 317ss.).

57 POLITOFF/ MATUS / RAMÍREZ, Lecciones, Parte General, cit. nota al pie nº 2, p. 532. Para efectos prácticos, en la p. 542 de ese texto puede verse, además, una tabla demostrativa del mínimun y máximun de cada grado de las penas divisibles. 
Proposiciones respecto de las cuestiones no resueltas por la Ley $\mathrm{N}^{\mathrm{o}} 20.084$

en materia de acumulación y orden de cumplimiento de las penas

Esta limitación se ha interpretado como una suerte de "garantía" de pena máxima para los menores que delinquen, atendida su edad al momento de la comisión del hecho y opera con independencia de las reglas de $\operatorname{los}_{\operatorname{grados}}{ }^{58}$ y con posterioridad a la pena determinada según el régimen concursal aplicable. ${ }^{59}$

A continuación, una vez determinado el concreto grado de la extensión temporal de la pena y, cuando corresponda, ajustando su duración a los máximos señalados en el art. 18 de la Ley $\mathrm{N}^{\mathrm{o}} 20.084$, debe procederse a la sustitución de loas penas establecidas para los adultos por el Código Penal y las Leyes Especiales, por alguna de las sanciones del art. $6^{\circ}$ de la Ley $\mathrm{N}^{\circ}$ 20.084 , conforme a los criterios que sus artículos 23 y 24 ofrecen. ${ }^{60}$

Si bien se mira, este proceso de sustitución de las penas legalmente determinadas por las sanciones de las Ley $\mathrm{N}^{\circ} 20.084$ es enteramente análogo al que opera entre las penas de adultos y las medidas alternativas establecidas en la Ley $\mathrm{N}^{\mathrm{o}}$ 18.216. En este aspecto, la única diferencia entre ambos sistemas sería que, en el caso de la Ley $\mathrm{N}^{0}$ 20.084, las penas no están siempre suficientemente concretadas en cuanto a su duración máxima, pues es posible que dicha concreción haya llegado sólo hasta el establecimiento del grado de duración temporal, si no es aplicable en la especie la limitación del art. 18 de la Ley № 20.084 .

Sin embargo, tratándose de una situación concursal o de reiteración de delitos, debería primeramente calcularse la pena en concreto dentro del grado a aplicar, antes de hacer la sustitución a que se refiere el artículo $6^{\circ}$ de la Ley $\mathrm{N}^{\mathrm{0}} 20.084$, pues, como vimos en los apartados anteriores, de otro modo no hay forma de determinar la extensión de la pena aplicable, ya que la única comparación posible entre el régimen del art. 74 CP y el 351 CPP es a partir de la pena

58 Por lo mismo, no parece adecuado, en este punto, realizar una "rebaja de grado" adicional a la establecida en las reglas generales y en el art. 21 de la Ley $\mathrm{N}^{\circ} 20.084$, para adecuar la pena a la extensión máxima prevista para los menores, como propone HORVITZ, "Determinación", cit. nota al pie n 56 , p. 104, sino que simplemente basta, para cumplir con la finalidad de la ley, con reducir a la máxima extensión permitida la pena legalmente determinada, quedando ésta, en concreto, fijada en 10 o 5 años, según la edad del menor infractor.

59 CERDA / CERDA, Sistema, p. 87, justifican la aplicación de los límites del art. 18 de la Ley № 20.084 como garantía máxima de duración de la pena, con independencia del régimen concursal aplicable y, particularmente, sobre la suma de las penas resultantes de la aplicación del "concurso material de delitos", "no sólo en atención a su menor culpabilidad, sino también a la necesidad de proteger su desarrollo, evitando exponerlo a una pena superior a 5 ó 10 años, según el caso, con independencia de la cantidad de delitos por los que se le condene"; a lo cual agregan el argumento de la literalidad del art. 22 de la Ley $\mathrm{N}^{\mathrm{o}} 20.084$, que contempla dicha limitación después de haberse hecho la remisión a las reglas generales de determinación de la pena del Código Penal (que incluyen las concursales), en el art. 21.

60 El detalle operativo de estos artículos, con acertados comentarios críticos acerca de la indeterminación general que parece presidir el sistema, puede verse en HORVITZ, "Determinación”, cit. nota al pie n 56, pp. 109-115. 
concreta determinada. Finalmente, para aplicar la limitación temporal del art. 18 de la Ley $\mathrm{N}^{\mathrm{o}}$ 20.084, en casos de aplicación exclusiva del régimen penológico del art. $74 \mathrm{CP}$, ello sólo sería lógicamente posible si, previamente, se hubiese hecho la "suma hipotética" de todas las penas correspondientes a las diversas infracciones, calculadas en concreto, pues dicha suma no es posible hacer "en grados".

No obstante lo anterior, el art. 21 de la Ley N 20.084 , excluye la aplicación, en la determinación de la pena, de la regla del art. $69 \mathrm{CP}$, que establece el modo de determinar la concreta cuantía de la pena dentro del grado correspondiente. ${ }^{61} \mathrm{El}$ propósito de esta exclusión, que parece ser sustituir los criterios generales de determinación de la pena en concreto del Código Penal por los específicos de la Ley $\mathrm{N}^{\mathrm{o}} 20.084$, podría tener sentido en los casos en que no existe un régimen concursal, pero en éstos produce el inconveniente de que deja al tribunal sin parámetros para la determinación de la pena en concreto, que en tales casos que ello debiera hacerse antes de su sustitución por las sanciones del art. $6^{\circ}$ de dicha ley, para hacer posible dicha sustitución.

Sin embargo, es posible argumentar, para los efectos de la Ley $\mathrm{N}^{0} 20.084$, que en ella existe un principio, manifestado a efectos de determinación de la pena en sus artículos 18, 20, 21 y 26, según el cual, para que el adolescente sea adecuadamente responsabilizado de sus actos y sometido a una intervención educativa con sentido, ${ }^{62}$ no necesita sufrir una pena de duración igual o mayor a la que la correspondería a un adulto en casos similares. Por lo tanto, a falta de los criterios que en el art. 69 del Código Penal se establecen para la concreción de la pena en el régimen de adultos, el tribunal sólo podría concretar éstas, una vez aplicadas las reglas de los arts. 50 a 55 y 67 CP, en el mínimo correspondiente, esto es, en la mínima extensión del grado aplicable o en la mínima extensión de su maximun, según correponda, pues con ello se logra suficientemente "responsabilizar" al menor y permitir la imposición de la sanción reintegradora que corresponda, sin que, en ningún caso, ello suponga que al menos la extensión teórica de la pena impuesta al menor excedería la de que, en similar caso (determinar la pena dentro de un grado), correspondería a un adulto.

61 POLITOFF/ MATUS / RAMÍREZ, Lecciones, Parte General, cit. nota al pie nº 2, p. 537.

62 Con todo, aquí no se pretenden afirmar que nuestro sistema de determinación de sanciones para adolescentes haya cumplido a cabalidad con dicho ideal, sino únicamente que se orienta al mismo, aunque no siempre con mucha fortuna. En efecto, así lo señaló el Primer Informe de la Comisión de Expertos Ley Responsabilidad Penal Adolescente, Octubre 2006: "El régimen de determinación de penas ofrece una infinidad de dudas interpretativas que han dado lugar a un importante debate entre los especialistas, no obstante lo cual persisten grados importantes de incertidumbre, que en la práctica también tenderán a agudizarse" (p. 11). En concreto, respecto a las limitaciones de este art. 18 de la Ley No 20.084, por una parte, parece "favorecerse" por regla general la comisión de hechos más graves o la reiteración de delitos, a través del límite temporal del art. 18; y por otra, al momento de la sustitución de las penas de adultos por las sanciones de menores no existen claros criterios para hacerla previsible y segura, deficiencias antes ya denunciadas por CILLERO, Miguel, "Comentario a la ley de responsabilidad penal de adolescentes", Revista Justicia y Derechos del Niño, nº 8 (2006), pp. 105-112, pp. 109-110. 
Proposiciones respecto de las cuestiones no resueltas por la Ley $\mathrm{N}^{\mathrm{o}} 20.084$

en materia de acumulación y orden de cumplimiento de las penas

Sólo sobre esta base sería posible, luego, realizar las operaciones necesarias para determinar hipotéticamente cuál régimen concursal supone la imposición de la "pena menor", si el de la reiteración del art. $351 \mathrm{CPP}$ o el del concurso real del art. $74 \mathrm{CP}$, en el caso que ambos sean aplicables, o sólo la "suma hipotética" de las penas que corresponderían conforme a este última disposición, en los restantes. Y una vez hecha estas operaciones, establecer si su resultado excede o no los límites máximos impuestos por el art. 18 de la Ley $N^{\circ} 20.084$, según la edad del menor, para ajustar a ellos, en definitiva, el máximo de la pena que correspondería al menor.

Finalmente, establecida la duración de las penas correspondientes al hecho, conforme a las reglas especiales dadas al efecto por la Ley $\mathrm{N}^{\circ} 20.084$, debe procederse a su sustitución por algunas de las sanciones de su artículo $6^{\circ}$ y a la fijación de la duración definitiva de ésta, ${ }^{63}$ según los criterios dados al efecto por sus artículos 23 y 24, como si se tratase de una sola pena, atendiendo únicamente al máximo de su duración.

Este es el caso de la sentencia de 29.10.2007 del Tribunal Oral en lo Penal de San Fernando, RIT 5-2007, donde, a solicitud de la defensa, se revisaron dos penas anteriormente impuestas conforme al régimen de adultos $\mathrm{y}$, primero, se rebajaron en su duración aplicando el principio de la retroactividad favorable del art. $18 \mathrm{CP}$ y la rebaja penológica del art. 21 de la Ley No 20.084 para, a continuación, unificar su duración total y, finalmente, sustituir la pena así unificada por la sanción correspondiente a su extensión temporal, según las reglas de los arts. 23 y 24 de la Ley $\mathrm{N}^{\mathrm{o}}$ 20.084. Lo mismo ocurre en la sentencia de 17.08.2007 del Tribunal Oral en lo Penal de Linares, RIT 28-2007: se adecua la pena a imponer a la regulación de la ley $\mathrm{N}^{\mathrm{0}} 20.084$, luego se "unifica" con dos condenas anteriores (transformadas también al sistema penal para adolescentes), se estima aplicable la regla del art. 351 CPP y, finalmente, la pena así "unificada", en atención a su duración temporal, es sustituída por una de las sanciones previstas en la ley $\mathrm{N}^{\mathrm{o}} 20.084 .{ }^{64}$

Sin embargo, no se me escapa ni tampoco se le debiera escapar al lector atento de la Ley $\mathrm{N}^{\mathrm{o}}$ 20.084, que ésta no ha tenido expresamente en consideración, para la determinación de la naturaleza de la sanción a imponer y su duración definitiva, las situaciones de reiteración de

63 En efecto, no sólo existen ciertas sanciones en la Ley $\mathrm{N}^{\circ} 20.084$, como la libertad asistida especial de su artículo 14 y ciertas formas de ejecutarlas (las sanciones mixtas del art. 19, por ejemplo), cuya duración concreta debe precisarse a posteriori, conforme a su propia regulación, sino también, en los casos normales en que sólo se ha determinado "un grado", es necesaria esta precisión a posteriori del quantum definitivo de la sanción a imponer.

64 La sutil diferencia de estos casos con el presupuesto que aquí se analiza, es que en ambos la "unidad del procedimiento" es ficta, ya que las penas que se "unifican" para la sustitución prevista en la Ley $\mathrm{N}^{\circ}$ 20.084, han sido dictadas con anterioridad, pero deben someterse a este procedimiento único posterior, atendido lo dispuesto en el artículo 18 del Código Penal, esto es, la aplicación retroactiva de la ley penal más favorable, en este caso, el sistema de responsabilidad penal para adolescentes. 
delitos en adolescentes, quizás bajo la suposición de que éstos cometerían pocos delitos y aisladamente, lo cual es manifiesto en el fraseo del artículo 24, cuyos criterios para determinar la naturaleza de la sanción a imponer, deja ver a las claras que se está suponiendo el enjuiciamiento del menor por un único "ilícito", "hecho" o "delito", y que, por lo tanto, sólo el tenor de su letra f) permitiría apreciar esta circunstancia a la hora de determinar la naturaleza de la sanción a imponer, al obligar poner atención a su idoneidad "para fortalecer el respeto del adolescente por los derechos y libertades de las personas y sus necesidades de desarrollo e integración social" ${ }^{65}$

\subsection{Unificación de sanciones en casos de dos o más procedimientos, regidos por la Ley $\mathbf{N}^{\circ}$ 20.084}

Así como la Ley $\mathrm{N}^{\mathrm{o}} 20.084$ no se ha puesto expresamente en el caso de la reiteración de delitos por parte del menor infractor, tampoco lo ha hecho respecto del procedimiento y consecuencias que derivan de la sustanciación de procedimientos diferentes que luego, por concurrir los ya estudiados requisitos del art. 164 COT, deban ser sometidos a una nueva consideración, en el mal llamado proceso de "unificación de penas".

65 Así también se entiende en el Considerando Sexto de la sentencia de 3.9.2007 del Tribunal Oral en lo Penal de Ovalle, RIT 22-2007, donde la cantidad de delitos reiterados por el adolescente (10) lo lleva a imponer el máximo de la sanción de internamiento en régimen cerrado (10 años). En cambio, COUSO, Jaime, "Principio educativo y (re)socialización en el derecho penal juvenil", Revista Justicia y Derechos del Niño, $n^{\circ} 8$ (2006), pp. 51-63, plantea, bajo el supuesto de que ni las sanciones penales propiamente tales ni las medidas educativas tradicionales permitirían cumplir empíricamente con el objetivo del principio que da nombre a su artículo y que se menciona entre las finalidades de las sanciones de la Ley $\mathrm{N}^{\circ} 20.084$ en su art. 20, que debe procurarse su empleo sólo como último recurso, prefiriendo la "despenalización" de los casos mediante la reparación u otras salidas semejantes, y aún las medidas "ambulatorias" a las de "encierro". Eso le lleva a considerar como positivo que aún en "los casos de adolescentes que han cometido ya varios delitos o que cometen uno pero de mayor gravedad, el empleo de medidas socioeducativas ambulatorias (aún si se efectúa en un contexto institucional como lo es la justicia) podría ser visto como una forma de relativa despenalización, pues de no imponerse esas medidas el adolescente podría ser encarcelado" (p. 54). A partir de estas afirmaciones, CERDA / CERDA, Sistema, cit. nota al pie $\mathrm{n}^{\circ} 57$, p. 93, afirman que en los casos de "criminalidad leve o de mediana gravedad habitual", "la principal necesidad es la prevención especial positiva, a través de una alternativa a la cárcel, con un mayor nivel de control que la aplicación del principio de oportunidad, orientada a entregar herramientas al adolescente para una vida futura sin delitos". No comparto el supuesto de estos autores y, por lo tanto, no creo posible compartir sus conclusiones, pues aún si se admite que el "encierro" no produce un efecto resocializador en el adolescente, y si se discute también empíricamente la viabilidad de las medidas "ambulatorias", tratándose de adolescentes que han hecho del delito parte de sus procesos de socialización, la externalidad positiva de que no se encuentren en condiciones de incurrir nuevamente en ellos, al menos durante un tiempo determinado, con la oportunidad de recibir herramientas y competencias para su vida futura que no recibirían de otra manera (aún siendo bajas las probabilidades de que dichas herramientas sean incorporadas efectivamente por el menor), parece llevarnos a la solución contraria, esto es, que el encierro puede ser útil y necesario en tales casos, tanto para el menor como para la comunidad. 
Proposiciones respecto de las cuestiones no resueltas por la Ley $\mathrm{N}^{\mathrm{o}} 20.084$

en materia de acumulación y orden de cumplimiento de las penas

A este respecto, la solución teórica congruente con las finalidades de las sanciones del sistema de justicia penal adolescente, que son la responsabilización de éste y su adecuada reintegración a la sociedad y no la suma meramente aritmética de castigos, sería la posibilidad de, una vez decidido el régimen concursal aplicable conforme a lo ya explicado, y considerando la total extensión de la pena que así resultaría aplicando las reglas del Código Penal con las limitaciones que impone el art. 22 de la Ley $\mathrm{N}^{\circ} 20.084$, sustituir esta pena hipotética por alguna de las sanciones del art. $6^{\circ}$ de la Ley $\mathrm{N}^{\circ} 20.084$, determinada en cuanto a su naturaleza y duración definitiva en conformidad con lo dispuesto en los artículos 19 y 23 a 26 de dicho cuerpo legal, y ejecutada en su conformidad.

Así se decidió, por ejemplo, en la sentencia del Juzgado de Garantía de Puente Alto de 4.08.2007, RIT No 8995-2006, considerando noveno, aplicando una sanción mixta, en un caso de reiteración de delitos de robo con fuerza. En este mismo fallo, se resolvió, además, en su considerando décimo, otra situación, derivada de la aplicación de la retroactividad favorable a una condena anterior a los delitos reiterados cuya sanción se unificó. Aquí se estimó que la pena correspondiente por ese delito sería la de libertad vigilada asistida por 300 días, la que ordenó cumplir inmediatamente después de la pena "unificada", consistente en una sanción mixta que terminaba, precisamente, con un tiempo de libertad vigilada asistida.

La sentencia es así coherente no sólo con las finalidades de la ley N 20.084, al "unificar" jurídicamente las sanciones correspondientes a los delitos reiterados, mediante sus sustitución con una única sanción mixta del régimen penal de adolescentes, sino también al ordenar la ejecución posterior, de la sanción de libertad vigilada asistida por el delito que ya tenía sentencia ejecutoriada, produciendo así, de facto, una "unificación material" de la ejecución de las sentencias, que permite cumplir la finalidad de la ley (responsabilización y reintegración).

Nótese, además, que el orden del cumplimiento de las sentencias decretado en este fallo también es coherente con la lógica de la regla del inciso segundo del artículo 74, que obliga a cumplir primero las penas privativas de libertad y, en segundo término, las restrictivas.

A esta solución no se opone el tenor del art. 164 COT, que, como hemos señalado, no ofrece un sistema propiamente tal de "unificación" de penas, sino de adecuación de la sentencia "posterior" al máximo de la pena que hubiese correspondido conforme al art. 351 CPP, si éste condujese a una pena "menor" de la determinada con la simple aplicación del art. 74 CP. En efecto, la limitación del art. 164 COT opera sólo hasta el momento de determinar la duración de las penas que correspondería aplicar, conforme al régimen general del Código Penal, las leyes especiales y lo dispuesto en los artículos 21 y 22 de la Ley $N^{\circ} 20.084$, pero nada dice acerca de cómo estas penas habrán de sustituírse por las sanciones contempladas en la Ley $\mathrm{N}^{0} 20.084$, cuyo régimen de sustitución atiende solamente a la duración temporal de la o las penas determinadas conforme a las reglas que para ello establece, según vimos en el apartado anterior, $\mathrm{y}$, por lo tanto, no puede ser modificado sin violentar el propósito de las sanciones que allí se 
establecen, que se dirige a la responsabilización y reintegración de la persona única del menor condenado y no a la pluralidad o unidad de hechos punibles por los cuales se le sanciona.

\subsection{Unificación de penas y sanciones en casos de dos o más procedimientos, regidos tanto por la Ley No 20.084 como por el Código Penal}

\subsubsection{El principio general}

El artículo $3^{\circ}$, de la Ley $N^{\circ} 20.084$, establece:

“Artículo $3^{\circ}$. Límites de edad a la responsabilidad. La presente ley se aplicará a quienes al momento en que se hubiere dado principio de ejecución del delito sean mayores de catorce y menores de dieciocho años, los que, para los efectos de esta ley, se consideran adolescentes. En el caso que el delito tenga su inicio entre los catorce y los dieciocho años del imputado y su consumación se prolongue en el tiempo más allá de los dieciocho años de edad, la legislación aplicable será la que rija para los imputados mayores de edad"

El principio que parece extraerse de esta disposición es sencillo: la Ley $N^{o} 20.084$, sus sanciones y régimen especial de procedimiento y ejecución, están destinadas a ser aplicables a los adolescentes, esto es, menores entre los catorce y dieciocho años de edad.

Los adolescentes son los sujetos a que se refiere el art. $1^{\circ}$ de la Convención sobre los Derechos del Niño y respecto a los cuales tienen sentido principios como el del "interés superior del adolescente" (art. $2^{\circ}$ de la Ley N ${ }^{\circ} 20.084$ ), sanciones que consisten en "la reprensión enérgica al adolescente" (art. $8^{\circ}$ de la Ley $\mathrm{N}^{\mathrm{0}} 20.084$ ), "la sujeción del adolescente al control de un delegado conforme a un plan de desarrollo personal basado en programas y servicios que favorezcan su integración social" (art. 13 Ley N²0.084), "la residencia obligatoria del adolescente en un centro de privación de libertad, sujeto a un programa de reinserción social" (art. 16 Ley $\mathrm{N}^{\circ}$ 20.084), la declaración de que "las sanciones y consecuencias que esta ley establece tienen por objeto hacer efectiva la responsabilidad de los adolescentes por los hechos delictivos que cometan, de tal manera que la sanción forme parte de una intervención socioeducativa amplia y orientada a la plena integración social" (art. 20 Ley No 20.084), y el hecho de que, "durante la ejecución de las sanciones que regula esta ley, el adolescente" tenga, entre otros "derechos", a "acceder a servicios educativos" (art. 49 Ley No 20.084).

Por lo tanto, desde el punto de vista abstracto, no parece corresponder a la lógica de este sistema la imposición a un adulto de una sanción dispuesta para un adolescente y cuya determinación se hace sustituyendo la pena de adulto que correspondería, tomando ya en cuenta la menor culpabilidad al momento de los hechos (la rebaja obligatoria en el marco penal del art. 21 de la Ley $\mathrm{N}^{\mathrm{o}} 20.084$ ) y las eventuales exenciones a que conduce el art. $4^{\circ}$ de la Ley $\mathrm{N}^{\circ}$ 20.084 , relativo a los delitos sexuales cometidos por adolescentes. 
Proposiciones respecto de las cuestiones no resueltas por la Ley $\mathrm{N}^{\mathrm{o}} 20.084$

en materia de acumulación y orden de cumplimiento de las penas

Lo anterior se ratifica en la disposición del art. 28 de la Ley $\mathrm{N}^{\circ} 20.084$, que establece:

“Artículo 28. Concurso de procedimientos. Si a una misma persona se le imputa una infracción sancionada por esta ley y un delito cometido siendo mayor de dieciocho años, la investigación y juzgamiento de estos hechos se regirán por las normas del Código Procesal Penal aplicable a los mayores de edad"

Desde este punto de vista, la disposición es casi tautológica: si el infractor no sólo es mayor de edad, sino que ha de ser juzgado por delitos cometidos siendo menor y siendo ya adulto, ha de considerarse como tal para la determinación del procedimiento a seguir. ${ }^{66}$

Por lo tanto, como en el juzgamiento de los mayores de edad les son aplicables las penas de los adultos, parece razonable asumir que, descontada la necesidad de la rebaja penológica obligatoria del art. 21 de la Ley $\mathrm{N}^{\mathrm{o}} 20.084$, en atención a la menor culpabilidad del autor al momento de los hechos, la regulación de las penas a imponer ha de hacerse conforme a las reglas de los adultos, conforme a lo visto en los apartados anteriores, particularmente en casos de concursos y reiteración de delitos.

En el caso de reiteración de delitos de la misma especie del art. 351 CPP, esta solución es todavía más claramente coherente con la del artículo $3^{\circ}$ de la Ley $\mathrm{N}^{\circ} 20.084$, pues se trata de situaciones en que, habiendo comenzado la actividad criminal siendo el autor adolescente y continuado en su edad adulta, ésta puede considerarse, en ciertos casos, "como un solo delito" o sancionarse con una única pena en los restantes, produciéndose la acumulación jurídica de las infracciones cometidas.

La historia del establecimiento de este artículo 28 de la Ley $\mathrm{N}^{\circ} 20.084^{67}$ no hace sino confirmar estas conclusiones y, al mismo tiempo, explica como un simple error de trascripción el hecho de que allí se haga mención únicamente al Código Procesal Penal y no también al Código Penal, aunque es relativamente claro que el "juzgamiento" como adulto de un infractor supone la aplicación de sus disposiciones.

66 Luego, sólo el corto tiempo de prescripción (art. $5^{\circ}$ Ley $\mathrm{N}^{\circ} 20.084$ ) que se establece para los delitos cometidos siendo menor de edad, parece justificar que no exista esta regla como disposición general y que, aunque el imputado sea mayor de edad, se pueda perseguir su responsabilidad conforme a las reglas de procedimiento del Título II de la Ley $\mathrm{N}^{\circ} 20.084$, siempre que no haya delinquido siendo adulto y antes de que exista sentencia ejecutoriada.

67 La Historia de esta Ley se encuentra publicada por la Biblioteca del Congreso Nacional en http:// www.bcn.cl/histley/lfs/hdl-20084/HL20084.pdf, y las citas que se hacen se encuentran numeradas conforme a este texto, citado en adelante como, Historia. 
En efecto, el Proyecto del Ejecutivo contemplaba una disposición general, en su artículo $9^{\text {o }},{ }^{68}$ acerca de los concursos entre infracciones cometidas siendo adolescente y adulto, que establecía un sistema penológico similar al del art. $351 \mathrm{CPP}$, con una clara tendencia a imponer, en definitiva una pena única de adultos y no de menores de edad. ${ }^{69}$ Durante la tramitación en la Cámara de Diputados, esta disposición fue objeto de varias indicaciones, tendientes a aclarar, precisamente, que el adulto que se encontraba en esta situación debía ser procesado y castigado como tal (aunque, para efectos de medidas cautelares se aplicase lo dispuesto en el Proyecto) y que, en el caso excepcional del adulto menor de 20 años, podía mantenerse el tratamiento de los adolescentes, en un régimen similar al de los adultos jóvenes en Alemania y España. ${ }^{70} \mathrm{La}$

68 El Mensaje correspondiente (Historia, cit. nota al pie $\mathrm{n}^{\circ}$ 68, p. 17) proponía lo siguiente: "Artículo 9.Concursos. El adolescente imputado de haber cometido una infracción a la ley penal será juzgado por los tribunales, en conformidad a los procedimientos especiales establecidos en esta Ley.

$\mathrm{Si}$ a una misma persona se le imputa una infracción sancionada por esta ley y un delito cometido siendo mayor de 18 años, la investigación y juzgamiento de estos hechos se regirá por las normas del Código Procesal Penal aplicable a los imputados mayores de edad. No obstante ello, la aplicación de medidas cautelares cuyo fundamento radica en una infracción regulada por la presente ley, se regirá por el párrafo 3 del Título III.

En caso de condenarse a una persona por hechos cometidos como adolescente y como adulto, se estará a las siguientes reglas:

a) La sanción o pena correspondiente a cada uno de estos hechos será determinada conforme a las reglas de la ley que le sea aplicable, imponiéndose sólo aquella que sea de carácter privativo de libertad.

b) En todo caso, si se impusiere más de una pena privativa de libertad, preferirá aquella que sea impuesta en razón del delito ejecutado como adulto, pudiendo ser aumentada hasta por un máximo de 2 años atendida la naturaleza y circunstancias de la infracción cometida como adolescente."

69 Historia, cit. nota al pie $\mathrm{n}^{\mathrm{o}} 68$, p. 79-82.

70 Historia, cit. nota al pie $\mathrm{n}^{\circ} 68$, p. 81, la propuesta en este último sentido fue hecha por el Diputado Bustos. La disposición aprobada en el Primer Informe de la Comisión (p. 83s.) quedó como sigue: "Artículo $9^{\circ}$.- Concursos. Si a una misma persona se le imputa una infracción sancionada por esta ley y un delito cometido siendo mayor de dieciocho años, la investigación y juzgamiento de estos hechos se regirá por las normas del Código Procesal Penal aplicables a los imputados mayores de edad, si tuviere veinte años o más. En caso contrario se regirá por las normas de procedimiento establecidas en la presente ley.

En caso de condenarse a una persona por hechos cometidos como adolescente y como adulto, se estará a las siguientes reglas:

a) La sanción o pena correspondiente a cada uno de estos hechos será determinada conforme a las reglas de la ley que le sea aplicable, imponiéndose sólo aquella que sea de carácter privativo de libertad.

b) En todo caso, si correspondiere más de una pena privativa de libertad, se impondrá aquella que se funde en el delito ejecutado como adulto, pudiendo ser aumentada hasta por un máximo de dos años atendida la naturaleza y circunstancias de la infracción cometida como adolescente.

c) Si no correspondiere imponer penas privativas de libertad, preferirá la pena que se funda en el delito cometido como adulto.

Para la aplicación de las reglas precedentes, en aquellos casos en que se hubiere concedido la remisión condicional de la pena establecida en la Ley $\mathrm{N}^{\circ} 18.216$, se considerará que dicha pena no es privativa de libertad.

Lo dispuesto en los incisos primero y segundo del presente artículo, se aplicará en caso que se cometa una nueva infracción penal durante el período de cumplimiento de una condena impuesta en base a la presente ley." 
Proposiciones respecto de las cuestiones no resueltas por la Ley $\mathrm{N}^{\mathrm{o}} 20.084$

en materia de acumulación y orden de cumplimiento de las penas

disposición así aprobada no volvió a ser objeto de indicaciones sino hasta su discusión en la Comisión de Constitución del Senado, donde se acumularon a su respecto siete indicaciones, la mayor parte de ellas tendientes a simplificar su redacción y a no hacer distinciones entre los adultos, para que todos ellos sean sometidos a las reglas generales, junto con dos del Ejecutivo, que procuraba separar la regulación concursal de la del cúmulo de procedimientos. ${ }^{71}$ Discutidas las indicaciones, se aprobaron por unanimidad las de los Senadores Chadwick, Espina y Horvath, que proponían reemplazar el artículo proyectado por uno que dispusiera sencillamente que "si a una misma persona mayor de 18 años se le imputan infracciones sancionadas por esta ley y delitos cometidos siendo mayor de 18 años, la investigación y juzgamiento de todos ellos se regirá por las normas aplicables a los mayores de edad," con la enmienda correspondiente a su traslado como artículo 28, junto con la indicación del Ejecutivo en torno a la forma de llevar adelante los procesos en tales casos. ${ }^{72}$ Posteriormente, el denominado "Grupo de Trabajo" encargado de la redacción de las proposiciones en materia de determinación de la pena durante la discusión del Segundo Informe de la Comisión de Constitución del Senado, planteó la necesidad de incorporar una norma concursal que estableciera precisamente la aplicación de las reglas generales de los artículos 74 y 75 CP, 351 CPP y 164 COT, propuesta que fue rechazada por la Comisión con el argumento de que "en el contexto del proyecto de ley en estudio, para los

71 Las indicaciones recibidas (Historia, cit. nota al pie $\mathrm{n}^{\circ} 68$, p. 523s.) fueron las siguientes:

"36.- De S.E. el Presidente de la República, para suprimir su inciso primero.

37.- De los Honorables Senadores señores Chadwick y Espina, y 38.- señor Horvath, para reemplazar su inciso primero por el siguiente:

“Artículo $9^{\circ}$.- Concursos. Si a una misma persona mayor de 18 años se le imputan infracciones sancionadas por esta ley y delitos cometidos siendo mayor de 18 años, la investigación y juzgamiento de todos ellos se regirá por las normas aplicables a los mayores de edad.".

39.- Del Honorable Senador señor Viera-Gallo, para sustituir su inciso cuarto por el siguiente:

"Si correspondiere la aplicación de más de una pena privativa de libertad, se impondrá la mayor de ellas. Sin embargo, si la sanción derivada de la infracción cometida como adolescente fuera la más extensa, podrá ser reducida hasta por un máximo de 2 años, atendida la naturaleza y circunstancias en que tuvo lugar, siempre que no se trate de un delito de los señalados en las letras a), b) y c) del artículo $7^{\circ}$ y que el adolescente haya tenido al momento de cometerlo más de 16 años."

40.- De S.E. el Presidente de la República, para reemplazar, en su inciso sexto, la palabra "establecida" por la frase "o la medida de libertad vigilada, establecidas".

41.- De S.E. el Presidente de la República, para sustituir, en su inciso séptimo, la frase "los incisos primero y segundo del" por el artículo "el".

42.- De S.E. el Presidente de la República, para intercalar, a continuación del artículo $9^{\circ}$, el siguiente, nuevo:

"Artículo...- Concurso de procedimientos. Si a una misma persona se le imputa una infracción sancionada por esta ley y un delito cometido siendo mayor de 18 años, la investigación y juzgamiento de estos hechos se regirá por las normas del Código Procesal Penal aplicable a los imputados mayores de edad. Por su parte, si en un mismo procedimiento se investiga la participación punible de personas mayores y menores de edad tendrá lugar lo dispuesto en los artículos 185 y 274 del Código Procesal Penal. En todo caso, si se hubiere determinado la investigación conjunta de los procesos, se ajustará la sustanciación a las reglas previstas en la presente ley."

72 Historia, cit. nota al pie $\mathrm{n}^{\circ} 68$, p. 652s. 
efectos de los concursos, se aplican precisamente las normas generales". ${ }^{73}$ De este modo, se aprobó en definitiva la actual norma del artículo 28 de la Ley $\mathrm{N}^{\circ} 20.084$, entendiendo que su texto comprendía las mencionadas indicaciones 37 y 38 de los Senadores Chadwick, Espina y Horvath, junto con la 42, del Ejecutivo. ${ }^{74}$

Sin embargo, el art. 56 de la Ley $\mathrm{N}^{\mathrm{o}}$ 20.084, parece establecer como regla general, el principio contrario, esto es, que el imputado mayor de edad por un hecho cometido siendo adolescente, "continuará sometido a las normas de esta ley" hasta el término del procedimiento respectivo. Ello significaría, en principio, que los mencionados artículos $3^{\circ}$ y 28 de la Ley $\mathrm{N}^{\circ}$ 20.084 sólo tendrían un ámbito de aplicación excepcional, quedando todas las otras situaciones de concurrencia regidas por este artículo 56 de la Ley $N^{\circ} 20.084$, respecto a los hechos punibles conforme a ella, y a las del Código Penal y el art. 351 del CPP, respecto a las restantes.

Empero, esta interpretación conduciría a los siguientes absurdos manifiestos, en casos de que una persona cometiese delitos siendo adolescente y luego siendo adulto, sin haber sido juzgado previamente por ninguno de ellos, siendo juzgado o terminando de serlo, cuando ya ha alcanzado la mayoría de edad:

a) Debieran aplicarse sanciones establecidas para adolescentes no ya a personas que acaban de entrar a la adultez, sino incluso a adultos hechos y derechos;

b) Aunque los hechos se juzgasen conforme a las normas procedimentales de los adultos, según lo dispuesto en el art. 28 de la Ley $\mathrm{N}^{\circ} 20.084$, se deberían aplicar sanciones de adolescentes a personas juzgadas como adultos;

c) No existiría una regla ni un criterio que permita determinar el orden de cumplimiento de las sanciones impuestas al imputado como adulto y como menor de edad;

d) Si para determinar ese orden se aplicase el criterio general del inciso segundo del art. $74 \mathrm{CP}$, debiera imponerse primero una pena privativa de libertad, en régimen carcelario de adultos, y luego pasar a una sanción de las de la Ley $\mathrm{N}^{\mathrm{o}} 20.084$, en régimen de adolescentes;

e) En este caso, además, los jóvenes adultos que están terminando de cumplir su sanción iniciada como adolescentes serían expuestos a ser "contaminados" por adultos provenientes del régimen carcelario común.

73 Historia, cit. nota al pie $\mathrm{n}^{0} 68$, p. 676s. La disposición rechazada era la siguiente: “Artículo 25 bis.Concurso. El concurso de delitos se regirá por lo dispuesto en los artículos 74 y 75 del Código Penal y 351 del Código Procesal Penal, debiendo, en todo, darse aplicación a lo previsto en el artículo 164 del Código Orgánico de Tribunales.

Para la aplicación de estas reglas se tendrá en consideración la sanción concreta que hubiere correspondido imponerse separadamente por cada delito."

74 Lo que se indica claramente en el texto que resume los acuerdos de la Comisión, en el que, junto con y que se transcribe, a continuación del texto del aprobado y actual artículo 28 de la Ley $\mathrm{N}^{\mathrm{o}} 20.094$, lo siguiente: "Indicaciones números 37, 38 y 42. (4 x 0)" (las negritas están así en el original: Historia, cit. nota al pie $n^{\circ} 68$, p. 820). 
Proposiciones respecto de las cuestiones no resueltas por la Ley $\mathrm{N}^{\mathrm{o}} 20.084$

en materia de acumulación y orden de cumplimiento de las penas

Luego, para evitar estos absurdos, no es posible otorgarle al art. 56 de la Ley N ${ }^{\circ} 20.084$ otro alcance que no sea el que parece haber tenido en vista el legislador, esto es, la regulación de la condena y su ejecución en los casos en que el imputado por delitos cometidos siendo menor de edad cumpla la mayoría de edad antes de la condena respectiva o, habiendo sido ya condenado, la cumpla durante su ejecución, para lo cual se ofrecen detalladas prescripciones. En definitiva, se trata de reconocer la evidencia de la literalidad de este artículo, que no hace referencia a ninguna situación concursal.

Contra lo anterior podría también argumentarse que, siendo imposible la combinación entre el sistema de justicia de adultos y el de adolescentes, debería elegirse entre el que sería más favorable al condenado, esto es, el de la justicia penal adolescente. Sin embargo, este argumento debe rechazarse por tres razones: primero, porque en estos casos no hay un problema de aplicación temporal de ley que permita esta clase de razonamiento (la ley aplicable estaba vigente antes de la comisión de cada delito); en segundo lugar, porque el presupuesto fáctico del sistema de justicia penal para adolescentes no existe, dado que el imputado y potencial condenado ya no es más un adolescente, sino un adulto; y en tercer lugar, porque en tales casos, habiendo pasado de la infancia a la adultez cometiendo más de un delito, parecen carecer de otro sentido que el retórico, la necesidad de ofrecer al condenado sanciones propias de los adolescentes, exponiendo, además, a quienes propiamente han sido condenados bajo esa condición, al contacto con personas que ha delinquido siendo ya adultas. ${ }^{75}$

6.3.2. Los casos particulares de concurrencia entre hechos cometidos durante la adolescencia y otros cometidos durante la adultez

a) Aplicación de la regla general: todos los hechos son sentenciados en un mismo procedimiento

75 El hecho de que por disposición del art. 56 de la Ley $\mathrm{N}^{\circ} 20.084$ sea posible, en el caso de que un menor a punto de cumplir dieciocho años sea castigado al cumplir los 22 (en el caso de crimen no prescrito, descubierto a última hora), no se opone a esta conclusión, pues esta solución expresa de la ley, es aplicable solamente al caso de imputación de delitos cometidos por el menor de edad y no al de la concurrencia de procedimientos de adultos y adolescentes del art. 28. Materialmente, además, los perniciosos efectos que conllevarían reunir a adultos que han cometido delitos como tales junto a otros que sólo los cometieron siendo adolescentes, no se producirían, pues siempre sería únicamente el caso de reunir adultos que cometieron delitos siendo adolescentes. Finalmente, la limitación etaria que el corto tiempo de prescripción conlleva, podría todavía justificar, aunque malamente, la imposición de sanciones resocializadoras a un joven adulto que no debiera ser mayor de 23 años al momento de la condena. Esta limitación etaria, en los casos de reiteración de delitos comenzada en la adolescencia no es posible asegurar, cuando los delitos se siguen cometiendo en la edad adulta. Finalmente, cabe la sospecha de que, respecto de mayores de edad, quizás lo más favorable no sea recurrir a la Ley $\mathrm{N}^{\circ} 20.084$, sino a las medidas alternativas de la Ley $\mathrm{N}^{\circ}$ 18.216, si son aplicables al caso. 
Según dispone el art. 28 de la Ley $\mathrm{N}^{\circ} 20.084$, en este caso se aplicará el régimen de adultos para la sustanciación del proceso y su juzgamiento. Sin embargo, como los hechos cometidos durante la menor edad se encuentran sometidos a la rebaja general del art. 21 de la Ley $\mathrm{N}^{\circ} 20.084$, antes de los cálculos correspondientes para determinar si operará el régimen concursal general del art. $74 \mathrm{CP}$ o el de la reiteración de delitos de la misma especie del art. $351 \mathrm{CPP}$, debe hacerse la rebaja de un grado que la disposición primeramente citada impone a la pena señalada por la ley para los delitos cometidos durante la adolescencia. Hecha la rebaja, no se harán, sin embargo, la sustitución de las penas a imponer según los arts. 23 y 24 de la Ley $\mathrm{N}^{\mathrm{o}} 20.084$, sino que se procederá a determinar el régimen concursal aplicable, según la regulación para los adultos, en la forma señalada en el apartado $\mathrm{n}^{\mathrm{o}} 3$ anterior.

b) Primer caso de aplicación del art. 164 COT, conforme al sentido de la regla general: la sentencia anterior corresponde al régimen de adultos, la posterior, al de la Ley $\mathrm{N}^{\mathrm{o}} 20.084$

Corresponde en este caso, conforme a lo dispuesto en el art. 164 COT, regular la extensión de la pena dictada en la sentencia posterior, de manera que no exceda la que correspondería de haberse juzgado conjuntamente los hechos. Pero como, conforme al art. 28 de la Ley $N^{\circ} 20.084$, al haberse tratado conjuntamente estos supuestos correspondería imponer por el hecho cometido siendo adolescente la pena correspondiente al régimen de adultos, rebajada en un grado pero sin sustituirla por alguna de las sanciones del art. $6^{\circ}$ de la Ley $\mathrm{N}^{\circ} 20.084$, ésta ha de calcularse de esta forma y ajustarse en su duración, de ser necesario, por concurrir los presupuestos del art. 351 CPP y determinar su régimen penológico una pena "menor" a la que correspondería de aplicar el art. $74 \mathrm{CP}$. En caso contrario, corresponde aplicar la pena correspondiente con la rebaja expresada, en el orden que el inciso segundo de esta última disposición determina.

De este modo, se obtiene el mismo régimen penológico en este caso que en el anterior, con estricto apego al principio de igualdad ante la ley y, al mismo tiempo, respetando la rebaja penológica que corresponde al menor que ha delinquido.

c) Segundo caso de aplicación del art. 164 COT, conforme al sentido de la regla general: la sentencia anterior corresponde al régimen de la Ley $\mathrm{N}^{\circ} 20.084$, la posterior, al del régimen de adultos

Este es, sin duda, el único caso que presentaría una perplejidad más allá de lo esperado, por dos razones: a) la posibilidad de que la sentencia anterior se esté ya ejecutando al momento de dictarse la posterior; $\mathrm{y}$ b) la aparente imposibilidad de modificar, conforme a la regla del art. $164 \mathrm{CPT}$, en la sentencia posterior la ejecutoria producida en la anterior.

Sin embargo, en caso de ser conocida por los tribunales competentes la circunstancia de que el imputado lo es también por hechos cometidos durante su adultez y que no han sido todavía sancionados, correspondería la aplicación en el procedimiento y juzgamiento de estos 
Proposiciones respecto de las cuestiones no resueltas por la Ley $\mathrm{N}^{\mathrm{o}} 20.084$

en materia de acumulación y orden de cumplimiento de las penas

hechos el régimen de adultos, conforme a lo dispuesto en el art. 28 de la Ley $\mathrm{N}^{\circ} 20.084$, respetando eso sí la rebaja penológica establecida en su artículo 21, en atención a la menor culpabilidad del autor al momento de los hechos. Luego, la sentencia posterior se encontraría en el caso de serlo con relación a una pena de adultos y operarían las mismas reglas que en el caso anterior.

No obstante, es posible que, por circunstancias fácticas ajenas al propósito de la ley, desconociendo el tribunal competente la imputación por delitos bajo el régimen de adultos, de hecho se haya dictado una sentencia anterior sin consideración a los señalado en el art. 28 de la Ley $N^{\circ} 20.084$.

En estos casos, el tribunal posterior no puede dejar de imponer la sanción del régimen de adultos que correspondería. Sin embargo, para determinar ésta, ha de ser posible su comparación con la anteriormente impuesta. Para ello ha de atenderse a la pena que, conforme al régimen de adultos se habría impuesto. Luego, realizar la comparación correspondiente según lo prescrito en el Art. 351 CPP, de ser aplicable y, después, adecuar la sentencia posterior al máximo que resultaría conforme a dicha disposición o no, según lo que resulte en definitiva como "pena menor" para el condenado.

A continuación, el Tribunal debería determinar dejar sin efecto las sanciones del régimen penal para adolescentes, impuestas en sustitución de la pena correspondiente al de adultos, y reemplazarla por la de adultos sustituída, determinado el orden de ejecución de las penas impuestas, si se estima aplicable lo dispuesto en el art. 74 CP, o la duración máxima de la pena única a cumplir, en conformidad con lo señalado en el art. $351 \mathrm{CPP}$.

Naturalmente, si estas resoluciones de carácter económico no son adoptadas por el tribunal posterior, corresponderá al competente para la ejecución de las penas adoptarlas. ${ }^{76}$

Esta sería la única forma de lograr una aplicación igualitaria de la ley y de su voluntad, expresada en el texto del Art. 28 de la Ley No 20.084 y en la historia de su establecimiento, de tratar de forma unitaria, conforme al régimen de adultos, los supuestos en que el menor que delinque lo hace nuevamente cuando ha obtenido la mayoría de edad, sin haber sido previamente condenado.

76 Esto significa, indirectamente, la posibilidad de facto de que un condenado se encuentre anómalamente cumpliendo condenas por los dos sistemas, si es que él mismo, su defensor o el Ministerio Público no se lo hacen saber oportunamente al tribunal "posterior". Sin embargo, ello no podrá durar demasiado tiempo y tarde o temprano el tribunal competente habrá de resolver sobre el asunto, seguramente a petición de la autoridad penitenciaria. 
560 Revista Ius et Praxis - aÑo 14 - № 2 